\title{
Evaluation of a Combined Cyclone \& Gas Filtration System for Particulate Removal in the Gasification Process
}

\author{
Reporting Period
}

March 14, 2001 - May 1, 2009

\section{Final Report}

May 6, 2013

Work Performed Under

DOE Award No. DE-FC26-02NT41583

For:

The U.S. Department of Energy

National Energy Technology Laboratory

Morgantown, West Virginia

\author{
Prepared by: \\ Jeffrey J. Rizzo \\ Reliability Engineer \\ Phillips66 Company \\ 444 West Sandford Ave \\ West Terre Haute, IN 47885
}


This report was prepared as an account of work sponsored by an agency of the United States Government. Neither the United States Government nor any agency thereof, nor any of their employees, makes any warranty, express or implied, or assumes any legal liability or responsibility for the accuracy, completeness, or usefulness of any information, apparatus, product, or process disclosed, or represents that its use would not infringe privately owned rights. Reference herein to any specific commercial product, process, or service by trade name, trademark, manufacturer, or otherwise does not necessarily constitute or imply its endorsement, recommendation, or favoring by the United States Government or any agency thereof. The views and opinions of authors expressed herein do not necessarily state or reflect those of the United States Government or any agency thereof. 


\section{Forward}

This document represents the final reporting for Slipstream Testing of a Combined Cyclone and Gas Filter System for Particulate Removal at the sgSolutions, LLC gasification facility completed by Phillips66 Company (P66). The U. S. Department of Energy (DOE) provided funding for this testing under Cooperative Agreement No. DE-FC26-02NT41583. The National Energy Technology Laboratory (NETL) provided the DOE program administration including Project Managers Jenny Tennant and Norman Popkie during the course of the Cyclone testing. The initial ConocoPhillips Company (COP) Project Director for the Cyclone and Slipstream testing was Michael J. Hickey. Other P66 Project Engineers and Operators who have been involved with the development of the Cyclone testing include Ron Herbanek, Mike Rooksberry, Gary Young, Rhett Beaumont, Kevin Possi, Jeffrey Rizzo, Art Love and Gary Taflinger. P66 would also like to acknowledge the assistance of Andy Bevis and personnel from Porvair Filtration Group. Jeffrey Rizzo of P66 prepared this final report. 


\begin{abstract}
Background

The Wabash gasification facility, owned and operated by sgSolutions LLC, is one of the largest single train solid fuel gasification facilities in the world capable of transforming 2,000 tons per day of petroleum coke or 2,600 tons per day of bituminous coal into synthetic gas for electrical power generation. The Wabash plant utilizes Phillips66 proprietary E-Gas ${ }^{\mathrm{TM}}$ Gasification Process to convert solid fuels such as petroleum coke or coal into synthetic gas that is fed to a combined cycle combustion turbine power generation facility. During plant startup in 1995, reliability issues were realized in the gas filtration portion of the gasification process. To address these issues, a slipstream test unit was constructed at the Wabash facility to test various filter designs, materials and process conditions for potential reliability improvement. The char filtration slipstream unit provided a way of testing new materials, maintenance procedures, and process changes without the risk of stopping commercial production in the facility. It also greatly reduced maintenance expenditures associated with full scale testing in the commercial plant. This char filtration slipstream unit was installed with assistance from the United States Department of Energy (built under DOE Contract No. DE-FC26-97FT34158) and began initial testing in November of 1997. It has proven to be extremely beneficial in the advancement of the E-Gas ${ }^{\mathrm{TM}}$ char removal technology by accurately predicting filter behavior and potential failure mechanisms that would occur in the commercial process.
\end{abstract}


After completing four (4) years of testing various filter types and configurations on numerous gasification feed stocks, a decision was made to investigate the economic and reliability effects of using a particulate removal gas cyclone upstream of the current gas filtration unit. A paper study had indicated that there was a real potential to lower both installed capital and operating costs by implementing a char cyclonefiltration hybrid unit in the E-Gas ${ }^{\mathrm{TM}}$ gasification process. These reductions would help to keep the E-Gas ${ }^{\mathrm{TM}}$ technology competitive among other coal-fired power generation technologies.

\section{Cyclone Test Objectives}

The Wabash combined cyclone and gas filtration slipstream test program was developed to provide design information, equipment specification and process control parameters of a hybrid cyclone and candle filter particulate removal system in the E-Gas ${ }^{\mathrm{TM}}$ gasification process that would provide the optimum performance and reliability for future commercial use. The test program objectives were as follows:

1. Evaluate the use of various cyclone materials of construction.

2. Establish the optimal cyclone efficiency that provides stable long term gas filter operation.

3. Determine the particle size distribution of the char separated by both the cyclone and candle filters. This will provide insight into cyclone efficiency and potential future plant design.

4. Determine the optimum filter media size requirements for the cyclone-filtration hybrid unit. 
5. Determine the appropriate char transfer rates for both the cyclone and filtration portions of the hybrid unit.

6. Develop operating procedures for the cyclone-filtration hybrid unit.

7. Compare the installed capital cost of a scaled-up commercial cyclone-filtration hybrid unit to the current gas filtration design without a cyclone unit, such as currently exists at the Wabash facility.

\section{Conclusions and Technical Insights}

The conclusions and technical insights of the char cyclone-filtration hybrid slipstream study were as follows:

1. A cyclone separator constructed of a stainless steel alloy was deemed unacceptable due to its high rate of wear. Another metal alloy was utilized for the fabrication of the second cyclone separator. The wear rate of that metal alloy was found to be acceptable for the purposes of this study. However, harder materials with greater abrasion resistance must be tested and evaluated to determine what would be an acceptable rate of wear within the commercial process.

2. The particle size distribution and cyclone efficiency were determined for the char cyclone-filtration hybrid unit to establish design specifications for future EGas $^{\mathrm{TM}}$ facilities.

3. The same candle type filter elements used in the commercial process had performed with acceptable efficiency in conjunction with the cyclone unit. The 
blinding life of those filter elements was determined to be at a lower rate than without the cyclone unit.

4. Char transfer rates were determined for both the cyclone and filtration portions of the hybrid unit to establish operational guidelines for future E-Gas ${ }^{\mathrm{TM}}$ facilities.

5. Operating procedures for the cyclone-filtration hybrid unit were developed as a result of this study. These procedures should be used as a guide to establish operating procedures for future E-Gas ${ }^{\mathrm{TM}}$ facilities.

6. The initial capital cost of a commercial scale cyclone-filtration hybrid unit was estimated to be $49 \%$ less than the capital cost of a gas filtration design without a cyclone unit, such as currently exists at the Wabash facility. 
Table of Contents

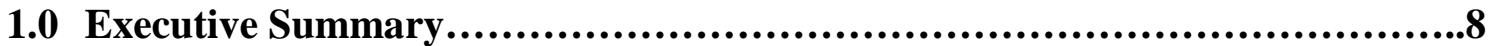

1.1 Background

1.2 Cyclone Project Description

1.3 Cyclone Test Objectives

1.4 Results

1.5 Conclusions and Technical Insights

2.0 Introduction....

2.1 Overview of the Wabash Gasification Facility

2.2 Cyclone Project Objectives

2.3 Cyclone Test Program

2.3.1 Cyclone Test Program Objectives

2.3.1 Cyclone Program Tasks

2.3.1 Evaluation Methods

2.3.1 Standard Operating Parameters

3.0 Project Description.

3.1 Project Overview

3.2 Cold Flow Process Review

3.3 Process Overview

3.4 Cyclone Vessel

3.5 Char Transfer System

3.6 Controls and Data Acquisition

4.0 Results.

4.1 Test Methodology

4.1.1. Filter Blinding Life Predictions

4.1.2. Filter Efficiency

4.1.3. Cyclone and Filter Reliability

4.1.4. Isokinetic Char Sampling

4.1.5. Char Recycle Rates

4.2. Operating Summary

4.2.1. Cold Flow Testing

4.2.2. Test Campaign 1

4.2.3. Test Campaign 2

4.2.4. Test Campaign 3

4.2.5. Test Campaign 4

4.2.6. Test Campaign 5

4.3. Design Guidelines

4.3.1. Design of a Commercial Unit

4.3.2. Equipment Specification and Process Parameters

4.4. Equipment Capital Cost Comparison

5.0 Conclusions and Technical Insights

5.1 Cyclone Validation

5.2 Cyclone Development

5.3 Filter Development

6.0 Recommendations

7.0 References. 
Evaluation of a Combined Cyclone \& Gas Filtration System for Particulate Removal in the Gasification Process

\section{List of Tables}

Table 2.3.4.1 Slipstream Operating Parameters

Table 4.3.2.1 $\quad$ Equipment Specification and Process Parameters for Cyclone Vessel

Table 4.3.2.2 Equipment Specification and Process Parameters for Filter Vessel

Table 4.3.2.3 Equipment Specification and Process Parameters for Blowback Gas Accumulator

Table 4.4.1 Capital Cost Comparison of Cyclone Unit versus Current Configuration

Table 5.3.1 Comparison of Filter Blinding Studies 


\section{List of Figures}

Figure 2.1.1 Block Line Diagram of the sgSolutions Gasification Facility

Figure 3.3.1 Slipstream Process Flow Diagram

Figure 3.2.2 Hybrid Cyclone \& Gas Filtration Slipstream Process Flow Diagram

Figure 4.2.1.1 Differential Pressure through the Cyclone Cold Flow Test System

Figure 4.2.1.2 Projected Differential Pressure through the Hybrid Cyclone Unit

Figure 4.2.2.1 Estimated Blinding Life of Filters from Test Campaign 1

Figure 4.2.3.1 Estimated Blinding Life of Filters from Test Campaign 2

Figure 4.2.4.1 Estimated Blinding Life of Filters from Test Campaign 3

Figure 4.2.4.2 Backup Filter Differential Pressure Test from Test Campaign 3

Figure 4.2.5.1 Estimated Blinding Life of Filters from Test Campaign 4

Figure 4.2.6.1 Estimated Blinding Life of Filters from Test Campaign 5

Figure 4.3.1.1 Proposed Commercial PFD for Combined Cyclone \& Gas Filtration System

\section{List of Photographs}

Photo 3.1.1 Cyclone Vessel and Gas Filtration Unit as installed at the Wabash Site

Photo 3.2.1 Cold Flow Test Unit Arrangement

Photo 3.4.1 Cyclone Vessel and Internal Components 


\section{Acronyms and Abbreviations}

$\begin{array}{ll}\text { BFW } & \text { Boiler Feed Water } \\ \text { COP } & \text { ConocoPhillips Company } \\ \text { COS } & \text { Carbonyl Sulfide } \\ \text { DOE } & \text { Department of Energy } \\ \text { DPT } & \text { Differential Pressure Transmitter } \\ \text { E-Gas } & \text { Formerly Dow Chemical Company's Gasification Technology, now } \\ & \text { owned and licensed by Phillips66 Company } \\ \text { F } & \text { Fahrenheit } \\ \text { FT } & \text { Flow Transmitter } \\ \text { HP } & \text { High Pressure } \\ \text { HTHRU } & \text { High Temperature Heat Recovery Unit } \\ \text { N2 } & \text { Nitrogen } \\ \text { NETL } & \text { National Energy Technology Laboratory } \\ \text { OEM } & \text { Original Equipment Manufacturer } \\ \text { P66 } & \text { Phillips66 Company } \\ \text { PDP } & \text { Process Design Package } \\ \text { PSI } & \text { Public Service of Indiana } \\ \text { psig } & \text { Pounds per Square Inch Gauge } \\ \text { PT } & \text { Pressure Transmitter } \\ \text { TT } & \text { Temperature Transmitter }\end{array}$




\subsection{Executive Summary}

\subsection{Background}

The Wabash gasification facility, owned and operated by sgSolutions LLC, is one of the largest single train solid fuel gasification facilities in the world capable of transforming 2,000 tons per day of petroleum coke or 2,600 tons per day of bituminous coal into synthetic gas for electrical power generation. The Wabash plant utilizes Phillips66 proprietary E-Gas ${ }^{\mathrm{TM}}$ Gasification Process to convert solid fuels such as petroleum coke or coal into synthetic gas that is fed to a combined cycle combustion turbine power generation facility. The gasification and power facility originally began as a joint venture program between Destec Energy Inc. of Houston, TX and PSI Energy Inc. of Plainfield, IN to participate in the United States Department of Energy's (DOE) Clean Coal Technology Initiative program to demonstrate coal gasification repowering of an existing pulverized coal-fired generating unit impacted by the Clean Air Act Amendments. After a brief startup period, successful operation was achieved at the plant in November of 1995. Plant ownership changed in 1997 as Destec Energy was sold by its parent company Dow Chemical Company to NGC Corporation. In 1998, NGC Corporation changed its name to become Dynegy, Inc. The plant changed ownership once again in 2000 as Global Energy acquired Dynegy's gasification assets. In 2003, ConocoPhillips obtained the rights to the intellectual property and the gasification process used at the Wabash facility. In 2005, sgSolutions, LLC and its parent company Wabash Valley Power Authority became the current majority owner and operator of the Wabash facility. 
During plant startup in 1995, reliability issues were realized in the gas filtration portion of the gasification process. To address these issues, a slipstream test unit was constructed at the Wabash facility to test various filter designs, materials and process conditions for potential reliability improvement. The char filtration slipstream unit provided a way of testing new materials, maintenance procedures, and process changes without the risk of stopping commercial production in the facility. It also greatly reduced maintenance expenditures associated with full scale testing in the commercial plant. This char filtration slipstream unit was installed with assistance from the United States Department of Energy (built under DOE Contract No. DE-FC26-97FT34158) and began initial testing in November of 1997. It has proven to be extremely beneficial in the advancement of the E-Gas ${ }^{\mathrm{TM}}$ char removal technology by accurately predicting filter behavior and potential failure mechanisms that would occur in the commercial process.

After completing four (4) years of testing various filter types and configurations on numerous gasification feed stocks, a decision was made to investigate the economic and reliability effects of using a particulate removal gas cyclone upstream of the current gas filtration unit. A paper study had indicated that there was a real potential to lower both installed capital and operating costs by implementing a char cyclonefiltration hybrid unit in the E-Gas ${ }^{\mathrm{TM}}$ gasification process. These reductions would help to keep the E-Gas ${ }^{\mathrm{TM}}$ technology competitive among other coal-fired power generation technologies. In 2002, the U.S. Department of Energy agreed to provide 
Evaluation of a Combined Cyclone \& Gas Filtration System for Particulate Removal in the Gasification Process

funding to support the design, construction and operation of a char removal gas cyclone that would be installed in the existing char filter slipstream system for testing at the Wabash facility. The unit was designed, constructed, and placed into operation in February of 2006. The overall objective of the project was to evaluate cyclone performance and its effect on filter reliability. An economic analysis of filter installation and operating costs was to be conducted based on the results of this study.

\subsection{Cyclone Project Description}

The Process Design Package (PDP) was developed in 2003 for the combined cyclone and gas filter project. Detailed design, material procurement and field construction were completed by the end of 2004. Commissioning and startup were delayed until January of 2006 due to issues associated with plant ownership changes. The first cyclone-filter tests were conducted in February of 2006.

During operation, the combined cyclone and gas filter slipstream receives particulate laden syngas from an isokinetically designed nozzle between the high temperature heat recovery unit and the commercial gas filter vessel. The syngas slipstream flow is directed into the cyclone vessel (V-153) where the centrifugal forces separate the gas and most of the char. This cyclone removes approximately 90-95\% of the char particles from the syngas slipstream where they are collected in a char transfer drum (D-153) located directly below the bottom of the separator. Level detectors are used on the transfer drum to monitor char accumulation. At a predetermined level or time, 
char is removed from the drum and recycled back into the commercial process using a high pressure transport gas. The syngas slipstream, still containing 5-10\% of the original char loading, exits the top of the cyclone and is directed into the gas filter vessel (V-159).

The gas filter vessel is capable of testing up to seven (7) full size candle filter elements in a single cluster or can be configured for multi-tiered arrangements. The char collected on the filter elements is periodically removed through the use of a high pressure blowback gas comprised of recycled syngas. This high pressure syngas is stored in an accumulator vessel (D-158) and transferred to the downstream side of the filter elements by fast acting blowback valves on a timed frequency. These valves are used to simulate the conditions of the full scale commercial unit. During the blowback filter regeneration process, the dislodged char falls to the bottom of the filter vessel (V-159) and into its associated char transfer drum (D159). As with D-153, similar level detectors are used on D-159 to signal a char transfer event that can be based on level or a pre-determined time increment. The char is forwarded back into the commercial process by means of a high pressure transport gas. The particulate free syngas flows out of the gas filter vessel and is directed through a back-up, or secondary, filter system to prevent any solids from exiting the slipstream unit. This "clean" syngas is then returned to the commercial process. 
Evaluation of a Combined Cyclone \& Gas Filtration System for Particulate Removal in the Gasification Process

A Mod5 digital control system, developed by the Dow Chemical Company, provides the automated control and operator interface with the char filtration slipstream unit. The control logic for pulse cleaning can be initiated manually, periodically, or at a selected filter differential pressure. A periodic time increment was the typical mode of operation for this controller. ${ }^{1}$

\subsection{Cyclone Test Objectives}

The Wabash combined cyclone and gas filtration slipstream test program was developed to provide design information, equipment specification and process control parameters of a hybrid cyclone and candle filter particulate removal system in the E-Gas ${ }^{\mathrm{TM}}$ gasification process that would provide the optimum performance and reliability for future commercial use. The test program objectives were as follows:

8. Evaluate the use of various cyclone materials of construction.

9. Establish the optimal cyclone efficiency that provides stable long term gas filter operation.

10. Determine the particle size distribution of the char separated by both the cyclone and candle filters. This will provide insight into cyclone efficiency and potential future plant design.

11. Determine the optimum filter media size requirements for the cyclone-filtration hybrid unit.

12. Determine the appropriate char transfer rates for both the cyclone and filtration portions of the hybrid unit. 
13. Develop operating procedures for the cyclone-filtration hybrid unit.

14. Compare the installed capital cost of a scaled-up commercial cyclone-filtration hybrid unit to the current gas filtration design without a cyclone unit, such as currently exists at the Wabash facility.

\subsection{Results}

The Wabash char cyclone-filtration hybrid slipstream began operation in February of 2006. The hybrid unit was used to complete five (5) different test campaigns totaling over 1,624 hours of operation. During the testing, the commercial plant was operated on a feedstock of petroleum coke.

As a result of the aforementioned test campaigns, candle filter blinding trends were established for three (3) different filter media elements over varying filter face velocities. In addition, wear rates were established for two (2) different types of cyclone materials of construction. Isokinetic char samples were also collected and analyzed from both the cyclone and gas filter char transfer drums to determine the particle size distribution and cyclone efficiency. Operation of the cyclone-filter hybrid unit provided insight into the appropriate char transfer rates for the combined system. A cost comparison was also made to demonstrate the potential cost savings that could be realized in future E-Gas ${ }^{\mathrm{TM}}$ plant designs with the addition of a cyclone unit. 


\subsection{Conclusions and Technical Insights}

The conclusions and technical insights of the char cyclone-filtration hybrid slipstream study were as follows:

7. A cyclone separator constructed of a stainless steel alloy was deemed unacceptable due to its high rate of wear. Another metal alloy was utilized for the fabrication of the second cyclone separator. The wear rate of that metal alloy was found to be acceptable for the purposes of this study. However, harder materials with greater abrasion resistance must be tested and evaluated to determine what would be an acceptable rate of wear within the commercial process.

8. The particle size distribution and cyclone efficiency were determined for the char cyclone-filtration hybrid unit to establish design specifications for future EGas $^{\mathrm{TM}}$ facilities.

9. The same candle type filter elements used in the commercial process had performed with acceptable efficiency in conjunction with the cyclone unit. The blinding life of those filter elements was determined to be at a lower rate than without the cyclone unit.

10. Char transfer rates were determined for both the cyclone and filtration portions of the hybrid unit to establish operational guidelines for future E-Gas ${ }^{\mathrm{TM}}$ facilities.

11. Operating procedures for the cyclone-filtration hybrid unit were developed as a result of this study. These procedures should be used as a guide to establish operating procedures for future E-Gas ${ }^{\mathrm{TM}}$ facilities. 
Evaluation of a Combined Cyclone \& Gas Filtration System for Particulate Removal in the Gasification Process

12. The initial capital cost of a commercial scale cyclone-filtration hybrid unit was estimated to be $49 \%$ less than the capital cost of a gas filtration design without a cyclone unit, such as currently exists at the Wabash facility. 


\subsection{Introduction}

\subsection{Overview of the Wabash Gasification Facility}

The Wabash gasification facility, owned and operated by sgSolutions LLC, is one of the largest single train solid fuel gasification facilities in the world capable of transforming 2,000 tons per day of petroleum coke or 2,600 tons per day of bituminous coal into synthetic gas for use as a fuel for electrical power generation. The facility originally began as a joint venture program between Destec Energy Inc. of Houston, TX and PSI Energy Inc. of Plainfield, IN to participate in the United States Department of Energy's (DOE) Clean Coal Technology Initiative program to demonstrate coal gasification repowering of an existing pulverized coal-fired generating unit impacted by the Clean Air Act Amendments. Operation of the facility began in November of 1995. Plant ownership changed in 1997 as Destec Energy was sold by its parent company Dow Chemical Company to NGC Corporation. In 1998, NGC Corporation changed its name to become Dynegy. The plant changed ownership once again in 2000 as Global Energy acquired Dynegy's gasification assets. In 2003, ConocoPhillips obtained the rights to the intellectual property and the gasification process that is used at the Wabash facility. In 2005, sgSolutions LLC and its parent company Wabash Valley Power Authority became the current majority owner and operator of the Wabash facility. A block diagram for the Phillips66 patented E-Gas ${ }^{\mathrm{TM}}$ Gasification Process is depicted in Figure 2.1.1.

The process begins with the introduction of petroleum coke, or coal, and recycled water into a grinding mill process to produce a solids suspended slurry. This slurry 
is transported to the gasifier where the slurry is mixed with oxygen from an Air

Separation Unit at high temperature, creating a reducing atmosphere for partial combustion.

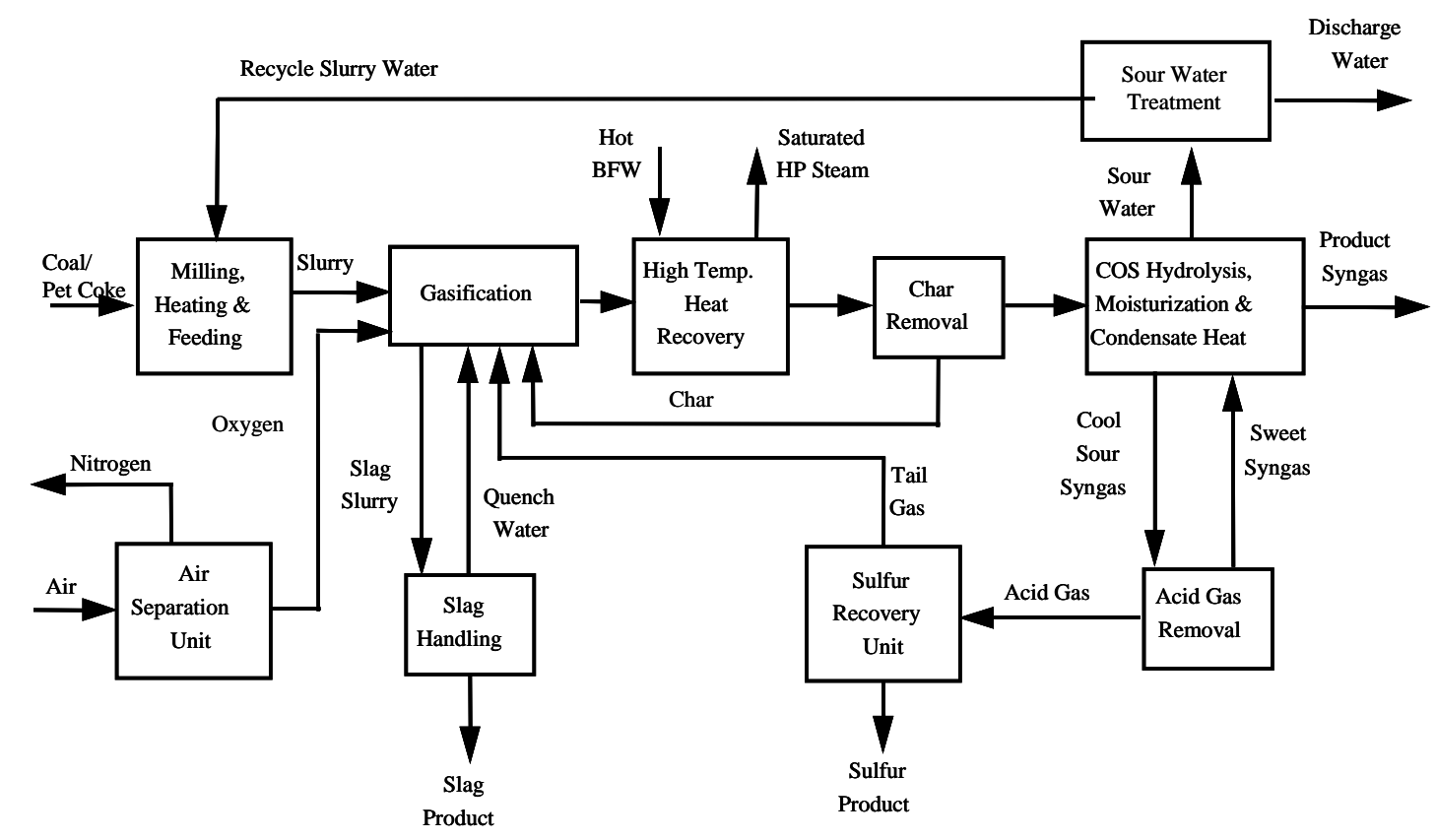

Figure 2.1.1—Block Line Diagram of the sgSolutions Gasification Facility

The petroleum coke (petcoke) is gasified by partial oxidation to produce synthetic gas (syngas) consisting primarily of hydrogen, carbon monoxide, carbon dioxide and water. Sulfur in the petcoke is converted almost totally to hydrogen sulfide and carbonyl sulfide. Nitrogen in the petcoke is converted to elemental nitrogen and ammonia. Ash from the petcoke leaves the gasifier in the form of slag, drains to the quench reactor and is removed from the process. The syngas produced in the gasifier contains entrained particulate (char) that is filtered out and recycled back to the gasifier in the char removal process. 
The High Temperature Heat Recovery Unit is used to recover a significant portion of the heat energy that was needed to drive the syngas reactions in the gasifier. The syngas enters a fire tube boiler where heat is removed and used to generate saturated steam. High pressure saturated steam is exported to the Power Block, superheated and expanded through a 1950's era Westinghouse steam turbine for electrical power generation as part of the original repowering project.

The cooled particulate-laden syngas then enters the char filtration unit where the char is removed from the syngas steam. Essentially, $100 \%$ of the char and entrained ash particulate is filtered from the syngas stream forming a cake on the exterior of the candle style filter elements. This cake is removed by periodic back-pulsing with high pressure recycled syngas. After the cake is dislodged from the filter, it drops, aided by gravity, to the bottom conical shaped outlet of the filter unit where it is drawn from the vessel and recycled back to the gasifier via high pressure transport syngas.

The final steps of the process include low temperature heat recovery, removal of the sulfur constituents from the product syngas, saturation and preheat prior to delivery and combustion in a General Electric 7FA gas turbine. The sulfur removal process results in a quality by-product. Molten sulfur, at greater than $99.5 \%$ purity, is recovered and sold as a raw material to a variety of end users. 


\subsection{Cyclone Program Objectives}

A char slipstream unit was originally constructed at the Wabash facility to address

reliability issues realized in the char filtration portion of the gasification process.

This slipstream unit provided a means of testing new materials, maintenance procedures and process changes without the risk of stopping commercial production in the facility. In addition, it greatly reduced the maintenance expenditures associated with full scale testing in the commercial plant. This unit was installed with assistance from the United States Department of Energy (built under DOE Contract No. DE-FC26-97FT34158) and began initial testing in November of 1997. It has proven to be extremely beneficial to the advancement of the E-Gas ${ }^{\mathrm{TM}}$ char filtration technology by accurately predicting filter behavior and potential failure mechanisms that would occur in the commercial process.

After completing four (4) years of testing, the char slipstream unit provided a number of insights into the gas filtration process as it pertains to the E-Gas ${ }^{\mathrm{TM}}$ technology. However, to remain competitive among other coal-fired power generation technologies, a decision was made to investigate the economic and reliability effects on both installed capital and operating costs by implementing a char cyclone-filtration hybrid unit in the E-Gas ${ }^{\mathrm{TM}}$ gasification process.

A DOE sponsored study titled, "Gasification Plant Cost and Performance Optimization” (Contract No. DE-AC26-99FT40342), was jointly conducted by Bechtel and Gasification Engineering Corporation (GEC). This study outlined 
improvements over the current gas filtration system at the Wabash facility that could significantly reduce both operating and maintenance costs of the facility. By utilizing a combined cyclone-filtration hybrid unit for char removal, both installed capital costs and plant availability could be improved over the existing technology. The potential cost savings would be attributed to both the reduced size of the filter elements and reduced char loading of the gas filtration unit. By reducing the surface area requirements of the filter system, the potential cost savings pertaining to maintenance (i.e. filter removal and installation, inventory costs and vessel repairs) would be inherent to the cyclone-filtration hybrid unit. In addition, the number of planned filter maintenance outages could be reduced, thereby increasing the plant's availability. Therefore, evaluating a combined cyclone and gas filtration slipstream at the Wabash facility would aid in the development of design specifications and operating procedures for new facilities as well as minimize the risk associated with the installation and startup of a new commercial process. Minimizing this risk would demonstrate to financial institutions and investors that this new process is a viable technology for investment. ${ }^{2}$

Similarly, the DOE sponsored study titled Slipstream Testing of Particulate Filters at the Wabash River Coal Gasification Repowering Project illustrated that the utilization of a char slipstream unit for testing various gas filter elements, maintenance procedures and process changes minimizes the risk of stopping commercial production in the facility. The char slipstream unit also demonstrated 
that the test data obtained was very comparable with results later observed within the commercial process.

Modifications were made to the existing char slipstream unit at the Wabash facility to incorporate a gas cyclone unit upstream of the current filtration slipstream. The char removal gas cyclone was designed to remove $90-95 \%$ of the char particles from the syngas slipstream with the remaining $5-10 \%$ to be removed by the gas filtration unit. This design incorporated the flexibility to adjust particle removal efficiency of the gas cyclone so that downstream filter size and operation could be optimized. ${ }^{1}$

Cyclone technology for particulate separation is more advanced than gas filtration, thereby reducing the risk for new plant design. However, a gas cyclone has never been successfully utilized in the E-Gas ${ }^{\mathrm{TM}}$ process for char particulate removal. Another purpose for this testing is to determine the design and operation of the filtration unit downstream of the gas cyclone where the removal of very fine particulate will be required. Experience has shown that filtering a fine particulate can be much more difficult than one containing a particle size distribution including coarse particulate. The ability to test various filter element designs and materials will be essential to char cyclone-filtration hybrid unit design for future E-Gas ${ }^{\mathrm{TM}}$ facilities with minimal risk. ${ }^{1}$ 


\subsection{Cyclone Test Program}

\subsubsection{Cyclone Test Program Objectives}

The Wabash combined cyclone and gas filtration slipstream test program was developed to provide design information, equipment specification and process control parameters of a hybrid cyclone and candle filter particulate removal system in the E-Gas ${ }^{\mathrm{TM}}$ gasification process that would provide the optimum performance and reliability for future commercial use. The test program objectives were as follows:

1. Evaluate the use of various cyclone materials of construction.

2. Establish the optimal cyclone efficiency that provides stable long term gas filter operation.

3. Determine the particle size distribution of the char separated by both the cyclone and candle filters. This will provide insight into cyclone efficiency and potential future plant design.

4. Determine the optimum filter media size requirements for the cyclonefiltration hybrid unit.

5. Determine the appropriate char transfer rates for both the cyclone and filtration portions of the hybrid unit.

6. Develop operating procedures for the cyclone-filtration hybrid unit.

7. Compare the installed capital cost of a scaled-up commercial cyclonefiltration hybrid unit to the current gas filtration design without a cyclone unit, such as the original char slipstream unit that existed at the Wabash facility. 


\subsubsection{Cyclone Test Program Tasks}

To complete the objectives listed in section 2.3.1, the Cyclone Test Program was divided into five (5) main tasks listed below:

Task 1.0—Cold Flow Testing

1.1. Develop a test plan for cold flow testing of char in a small scale model cyclone to establish operating characteristics for the char cyclonefiltration hybrid slipstream unit.

1.2. Perform cold flow bench scale model testing using particulate material from operation of the Wabash plant.

1.3. Based upon the results of the cold flow tests, determine appropriate process parameters for slipstream testing and to determine the size of the gas cyclone unit.

\section{Task 2.0_-Process Evaluation and Engineering}

2.1. Review the existing char slipstream unit to determine the system and physical requirements for modifying the slipstream to include a char removal gas cyclone unit.

2.2. Use the results of Task 2.1 as well as Task 1.0 to design the modification to the existing char slipstream unit and provide equipment specifications.

\section{Task 3.0-Char Slipstream Unit Modification}

3.1. Procure all required equipment and material including char removal gas cyclone and gas filter elements. 
3.2. Modify existing Wabash char slipstream unit for testing of the char cyclone-filtration hybrid unit.

3.3. Perform system checks (pressure testing, loop checks, etc.) to verify correct installation and system modification. Train plant personnel on the operation of the char cyclone-filtration hybrid unit.

\section{Task 4.0-Slipstream Testing}

4.1. Develop and execute a test plan for the char cyclone-filtration hybrid unit that will meet the above stated objectives.

4.2. Implement modifications to the system as necessary to optimize the test plan.

\section{Task 5.0_Data Analysis and Reporting}

5.1. Compile and analyze the data obtained in Task 4.0.

5.2. Based upon the analysis in Task 5.1, develop design guidelines, equipment specification and process parameters for use of a char cyclone-filtration hybrid unit.

\subsubsection{Evaluation Methods}

The following methods were used to evaluate the cyclone operation and filter elements tested in the Wabash char cyclone-filtration hybrid slipstream unit:

1. The plant's Mod5 digital control and data acquisition systems were used to collect operating data from the char cyclone-filtration hybrid unit. The data was used to calculate blinding rates of the gas filter elements located 
downstream of the gas cyclone unit. Those blinding rates were compared to those of the filter elements used in the commercial process.

2. Isokinetic char samples were collected and analyzed from both the cyclone and filter unit char transfer drums to determine particle size distribution and cyclone efficiency. Particle size distribution analyses of the char samples were completed using an electronic liquid particle counter.

\subsubsection{Standard Operating Parameters}

Table 2.3.4.1 summarizes the standard operating parameters for the Wabash combined char cyclone and filtration slipstream.

Table 2.3.4.1 Slipstream Operating Parameters

\begin{tabular}{|l|c|}
\hline Filter Vessel Temperature & $640-780 \mathrm{~F}$ \\
\hline Filter Vessel Pressure & $350-410 \mathrm{psig}$ \\
\hline Filter Inlet Mass Flow & $2242 \mathrm{lb} / \mathrm{hr}$ \\
\hline Filter Face Velocity & $2.5-5.0 \mathrm{fpm}$ \\
\hline Char Solids Loading & $37-39 \mathrm{lb} / \mathrm{hr}$ \\
\hline Blowback Gas Pressure & $775-880 \mathrm{psig}$ \\
\hline Blowback Gas Temperature & $280-390 \mathrm{~F}$ \\
\hline Blowback Duration & $250-350 \mathrm{msec}$. \\
\hline Blowback Cycle Time & $84 \mathrm{sec} .($ total $)$ \\
\hline Char Bulk Density & $12.5 \mathrm{lb} / \mathrm{ft}^{3}$ \\
\hline Char Mean Particle Size & $20-25 \mu$ \\
\hline
\end{tabular}




\subsection{Project Description}

\subsection{Project Overview}

After four (4) years of testing various filter types and configurations on numerous gasification feed stocks utilizing the char slipstream unit, an investigation began into the use of a gas cyclone unit upstream of the current gas filtration unit in the EGas $^{\mathrm{TM}}$ process. The potential cost savings associated with a combined char cyclonefiltration hybrid unit through lower capital and operating costs for future facilities would keep E-Gas ${ }^{\mathrm{TM}}$ technology competitive among other coal-fired power generation technologies. In 2002, the U.S. Department of Energy agreed to provide funding to support the design, construction and operation of a char removal gas cyclone that would be installed upstream of the existing char filter slipstream for testing at the Wabash facility (built under DOE Contract No. DE-FC2602NT41583).

Since its installation, the char slipstream unit had proven to be extremely beneficial in the advancement of the E-Gas ${ }^{\mathrm{TM}}$ char removal technology by accurately predicting the behavior and potential failure mechanisms that would occur in the commercial process. The new gas cyclone unit would need to be designed and integrated into the pre-existing char slipstream unit. It would need to be flexible enough to handle various gas cyclones of different materials of construction and cyclone efficiencies. 
The Process Design Package (PDP) was developed in 2003 for the combined gas cyclone and filtration slipstream by engineers at the Wabash facility. The design of the char cyclone-filtration hybrid unit was awarded in June of 2003, after which cold flow testing and detailed design of the cyclone vessel for delivery to the facility began. It was also around this time that ConocoPhillips obtained the rights to the intellectual property and gasification process used at the Wabash facility. After the transition in the early part of third quarter of 2003, ConocoPhillips began to work on the detailed design of the piping and support systems associated with the gas cyclone addition. Detailed designs and material procurement continued through the third quarter of 2004. Construction began and was completed by year end. However, commissioning and startup were delayed until January of 2006 due to a reorganization of the Wabash plant ownership. The first char cyclone-filtration hybrid unit tests began in February of 2006. 

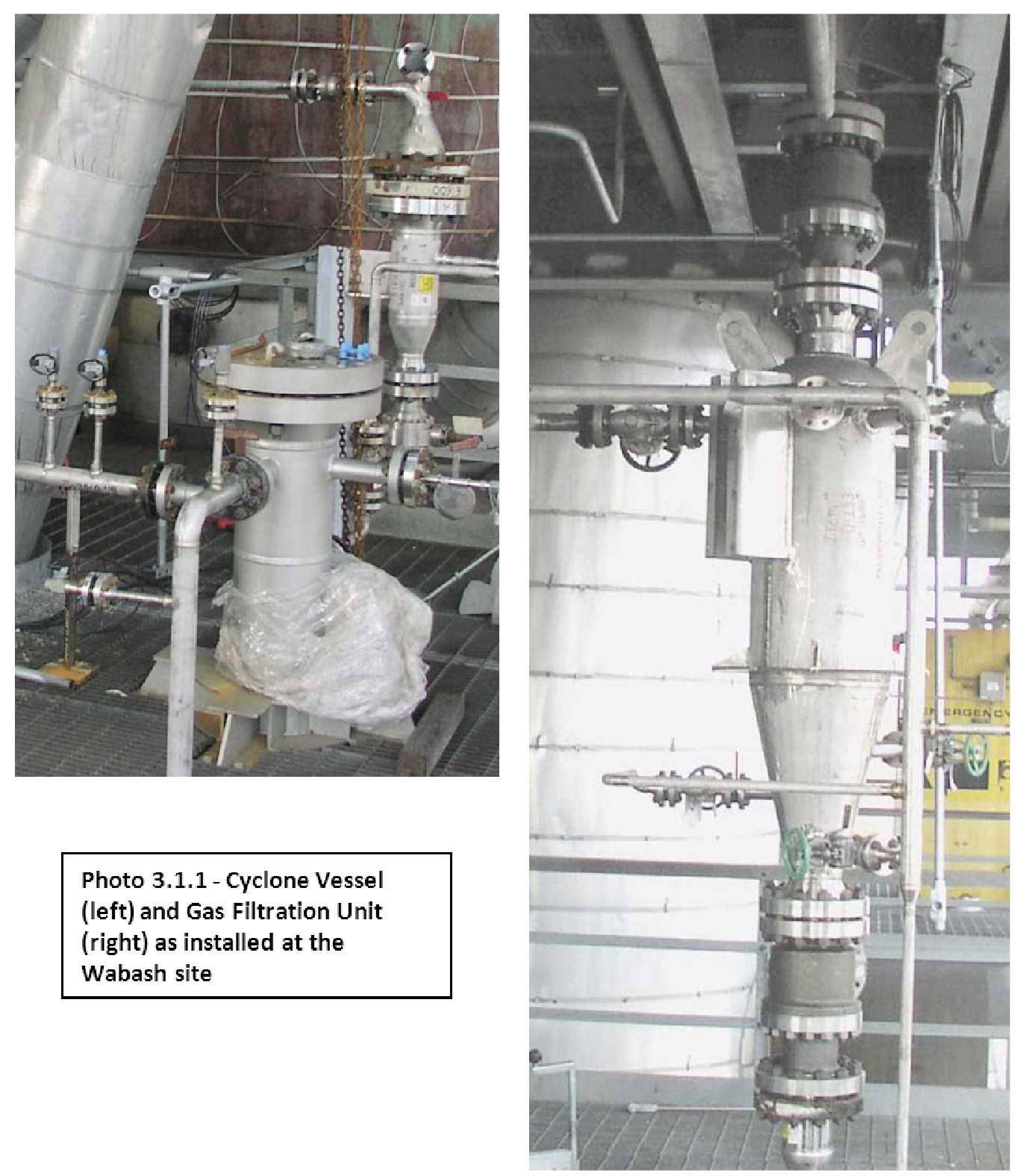

Photo 3.1.1 - Cyclone Vessel (left) and Gas Filtration Unit (right) as installed at the Wabash site

\subsection{Cold Flow Process Review}

Cold flow testing was performed by an outside contractor for ConocoPhillips. This testing was conducted to predict the pressure drop that would be seen across the gas cyclone during operation and the cyclone efficiency. Computer based models of both the bench scale cold flow testing unit and the Wabash gas cyclone unit were developed to predict both differential pressure and cyclone efficiency. These 
theoretical models were validated with laboratory testing completed on a bench scale cold flow testing unit, which was built to the same scale as the gas cyclone designed for the Wabash slipstream unit. Due to the handling requirements of char, a simulated test sample comprised of the same particle distribution as a char sample provided by the Wabash facility was used for the bench scale cold flow testing. This simulated sample was mixed with air and directed through the gas cyclone at various rates, temperatures, and pressures lower than that of the Wabash slipstream unit. The data collected was used to draw comparisons between the theoretical computer based models and to determine the appropriate process parameters for the char cyclone-filtration hybrid slipstream unit in the field.

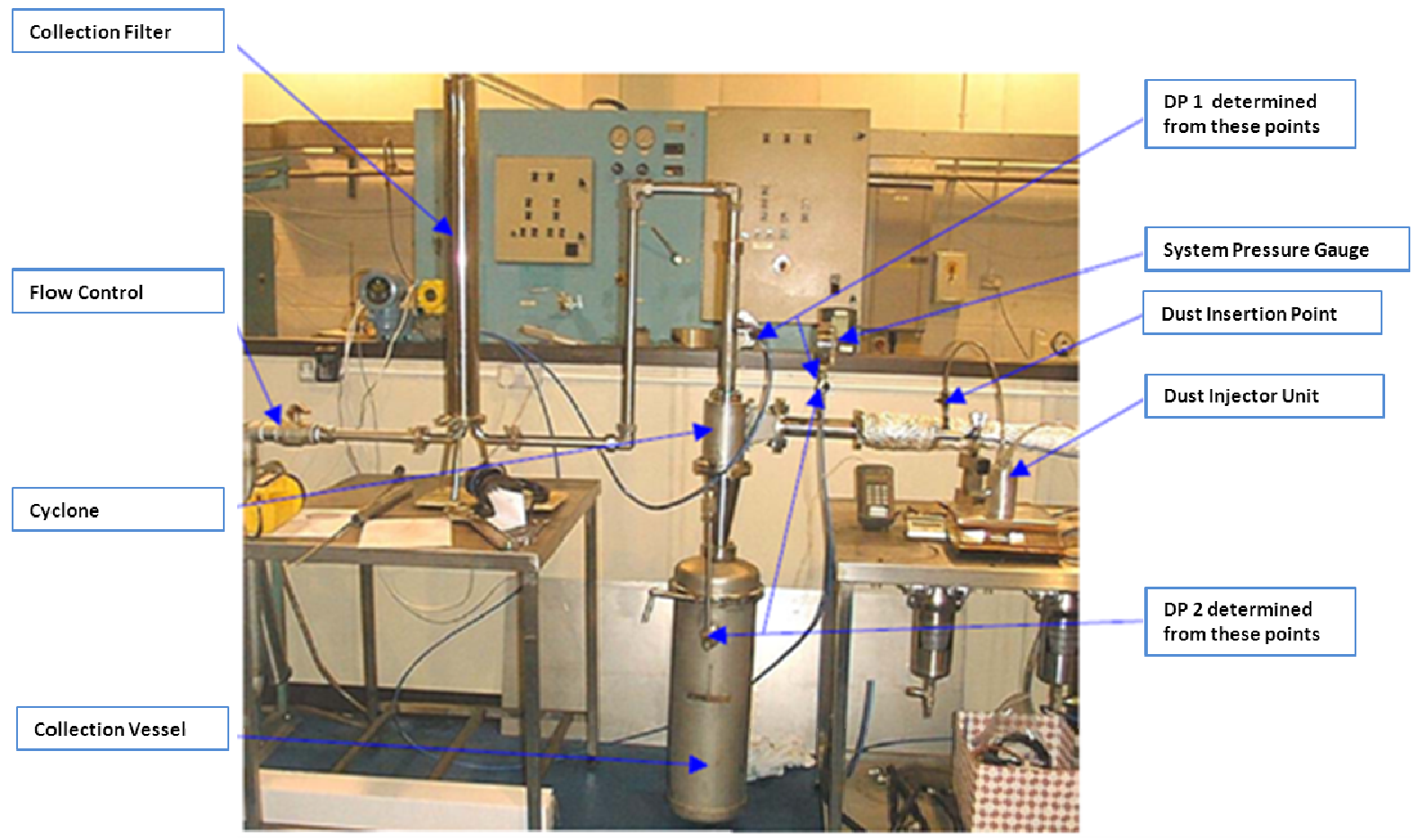

Photo 3.3.1 - Cold Flow Test Unit Arrangement 
Evaluation of a Combined Cyclone \& Gas Filtration System for Particulate Removal in the Gasification Process

\subsection{Process Overview}

Figure 3.3.1 illustrates the char slipstream unit as it was originally installed at the Wabash facility.

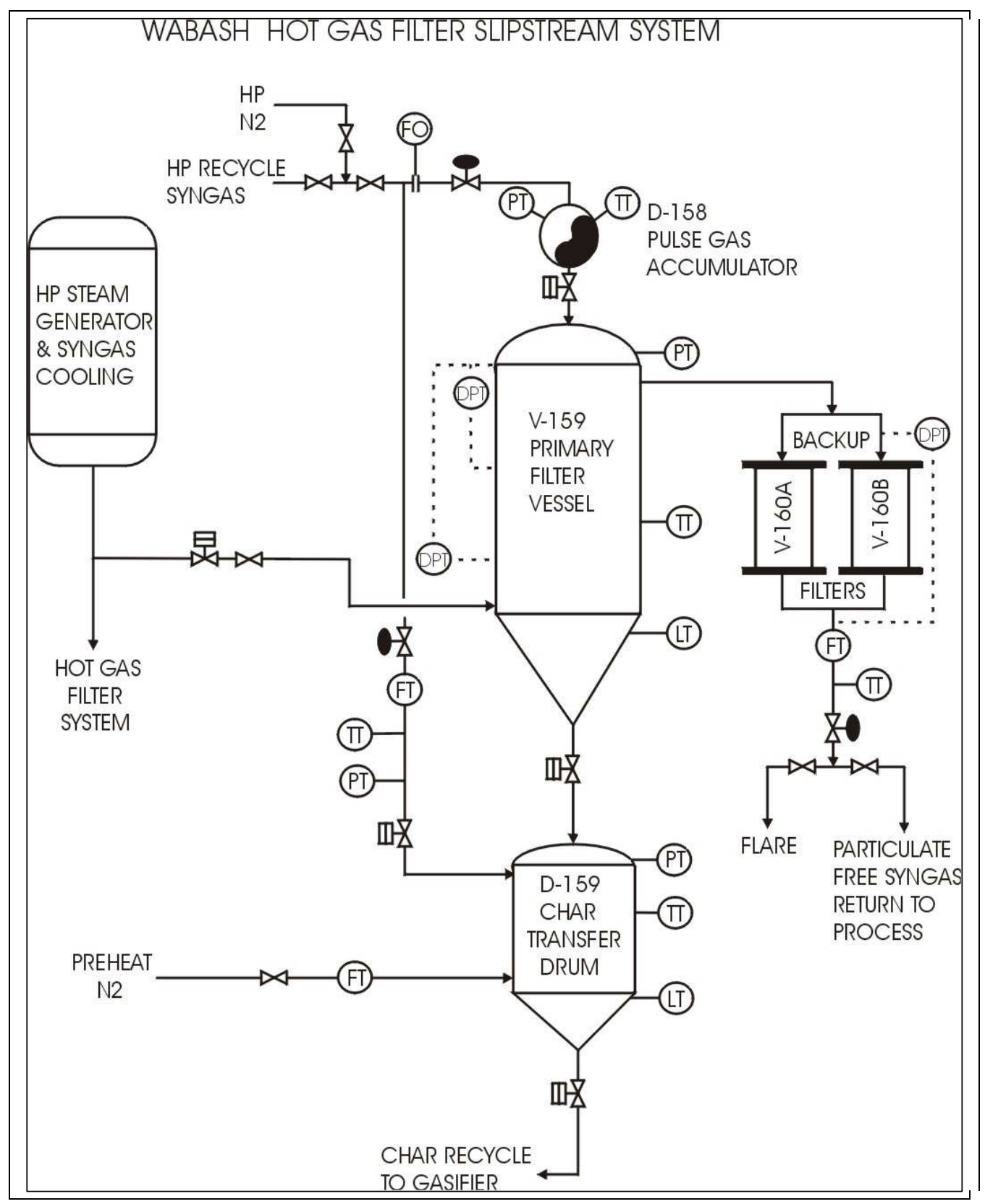

Figure 3.3.1 Char Slipstream Process Flow Diagram 
The char slipstream unit was designed to receive the same particulate laden syngas as is fed to the commercial particulate removal system. This raw syngas is removed from the process just upstream of the commercial gas filtration unit through an isokinetically designed nozzle. The entrained particulates in the syngas stream consist of entrained ash from the gasifier first stage process and partially reacted petcoke particles from the second stage process. This particulate matter, high in carbon, is classified as char.

As in the commercial process, the cooled particulate-laden syngas enters the slipstream gas filtration unit, V-159, at $650^{\circ}-800^{\circ} \mathrm{F}$ and $360-420 \mathrm{psig}$. The raw syngas continues through an internal gas distribution system that directs the flow downward over the outer surface of the candle style filter elements. Essentially, $100 \%$ of the char and ash is filtered from the syngas stream, forming a cake on the exterior of the candle style filter elements, as it flows through the filters and into the clean gas plenum. The particulate free syngas leaves V-159 where it flows through a secondary, or backup, filtration system (V-160A/B) and is recycled back into the commercial process. The aforementioned cake that forms on the primary filter elements is removed by periodic back-pulsing with high pressure syngas (D-158). This is the same high pressure syngas as used in the commercial process. The dislodged cake from the filter elements falls to the lower section of V-159 and into the Gas filter Char Transfer Drum, D-159. The char is collected in D-159 for a specified period of time before it is transferred back into the commercial process using high pressure transport syngas. In addition, the char slipstream unit is tied into

${ }^{1}$ Hickey, Michael J. Slipstream Testing of Particulate Filters at the Wabash River Coal Gasification Project. 2003 
Evaluation of a Combined Cyclone \& Gas Filtration System for Particulate Removal in the Gasification Process

both the plant nitrogen and flare systems, enabling the unit to be purged and preheated up to process temperatures.

The process of the char slipstream unit remains very similar to its original installation with the addition of the particulate removal gas cyclone. Figure 3.3.2 illustrates the combined cyclone and gas filtration slipstream as installed at the Wabash facility.

${ }^{1}$ Hickey, Michael J. Slipstream Testing of Particulate Filters at the Wabash River Coal Gasification Project. 2003 


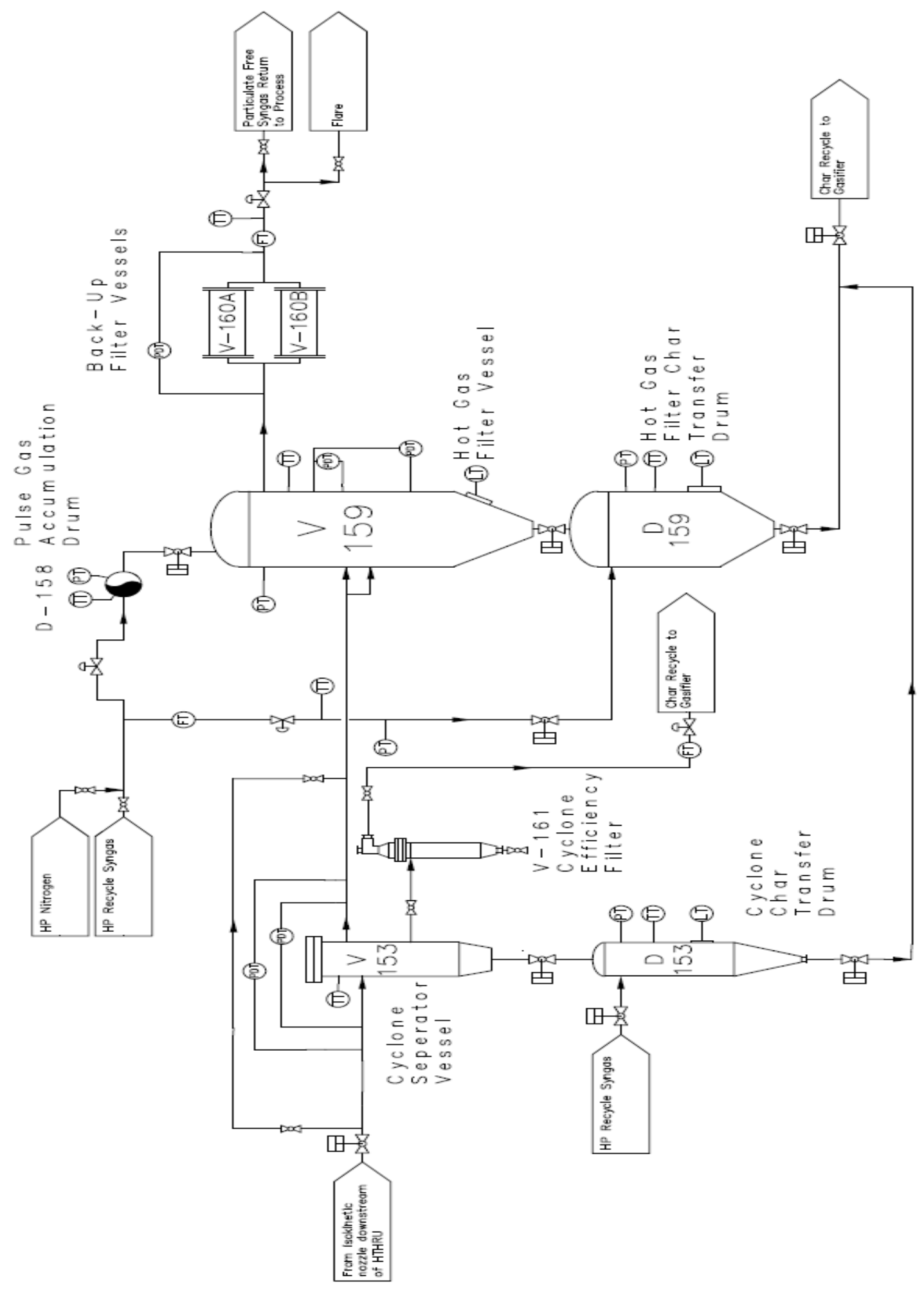

Figure 3.2.2 - Combined Cyclone and Gas Filtration Slipstream Process Flow Diagram 
With the addition of a particulate removal gas cyclone, the cooled particulate-laden syngas is removed from the commercial process through the same aforementioned isokinetically designed nozzle and enters the particulate removal gas cyclone unit, $\mathrm{V}-153$, at $650^{\circ}-800^{\circ} \mathrm{F}$ and $360-420 \mathrm{psig}$. The syngas enters the inlet of a gas cyclone that places a rotation on the syngas flow. The centrifugal forces created by the rotation cause the larger particulate to move to the outside wall of the gas cyclone, thereby removing approximately $90-95 \%$ of the particulates from the slipstream syngas. The particulates subsequently exit out the bottom of the V-153 to the Cyclone Char Transfer Drum, D-153. The char collected in D-153 is stored for a specified period of time before it is transferred back into the commercial process using high pressure transport syngas.

The slipstream syngas, with 5-10\% of the particulates remaining flows upward through a vortex finder and exits the V-153 vessel. The slipstream syngas then enters the gas filtration unit, $\mathrm{V}-159$, at $650^{\circ}-800^{\circ} \mathrm{F}$ and $360-420$ psig under the same process as described in the original configuration.

A vent line extending from the bottom portion of the V-153 transports a small amount of particulate laden syngas to a Cyclone Efficiency Filter Vessel, V-161. This vessel contains a single candle filter used to remove the particulate in the syngas stream. The particulate free syngas leaves the V-161 and is recycled back into the commercial process. The amount of syngas flow through the vent line is metered by a control valve for the purpose of adjusting the efficiency of the char 
removal gas cyclone. In addition, just as with the Char Slipstream Unit, the Char Cyclone-Filtration Hybrid Unit was tied into the plant nitrogen and flare systems, enabling the unit to be purged and preheated up to process temperatures.

\subsection{Particulate Removal Gas Cyclone Vessel}

The particulate removal gas cyclone unit, V-153, consists of a 10-inch diameter by 5-feet tall pressure vessel designed to the operating conditions listed in Table 2.3.4.1.

The cyclone design applied in the application is a tangential inlet, reverse flow type, based on the Stairmand cyclone design ${ }^{5}$. The cyclone itself is fitted into a pressure vessel. That vessel utilizes a single tube sheet design with the gas cyclone to remove $90 \%$ $95 \%$ of the particulates from the syngas. The inlet nozzle above the tube sheet directs the particulate laden syngas flow into a removable gas cyclone that is secured to the tube sheet. The particulate-laden syngas enters the inlet of the gas cyclone that places a rotation on the syngas flow. The centrifugal forces created by the rotation cause the larger sized particulate to move to the outside wall of the gas cyclone within the primary vortex, thereby removing $90 \%-95 \%$ of the particulates from the syngas. The larger sized particulates exit the vessel via the primary vortex and
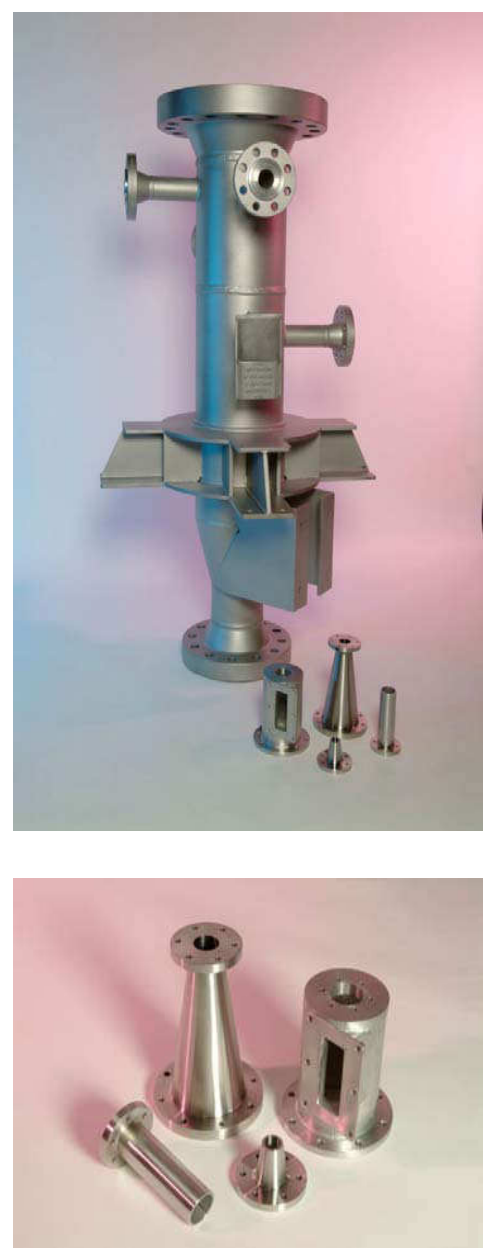

Photo 3.4.1 - Cyclone Vessel and Internal Components 
into a collection drum. The slipstream syngas, with approximately 5\%-10\% of the smaller sized remaining particulates, creates a secondary vortex within the center of the gas cyclone that rotates in the opposite direction of the primary vortex. This slipstream syngas exits the cyclone through a vortex finder, continues through the outlet nozzle of the gas cyclone vessel, and continues to the inlet of the gas filtration unit.

A second outlet nozzle is located near the bottom portion of the particulate removal gas cyclone. The purpose of this nozzle is for tuning the cyclone efficiency. A vent line extends from this nozzle to the Cyclone Efficiency Filter Vessel, V-161. The cyclone efficiency is tuned by directing a portion of the incoming particulate laden syngas through this line and into the V-161. The V-161 is constructed of a 6-inch diameter by 25 -inch tall pipe designed to the operating conditions listed in Table 2.3.4.1 and able to accommodate a single candle filter. The particulate-laden syngas enters V-161 and continues through an internal gas distribution system that directs the flow downward over the outer surface of the single candle style filter element to remove any particulate that would be carried over from the outlet of $\mathrm{V}-153$. The particulate free syngas would continue out the top of V-161 and recycle back into the commercial process via a control valve. As previously mentioned, the control valve is used to meter the syngas flow through the V-161. Subsequently, the V-161 is placed upstream of the tuning control valve to reduce the wear and extend its service life. 
Evaluation of a Combined Cyclone \& Gas Filtration System for Particulate Removal in the Gasification Process

The V-153 is inherently designed with the flexibility to easily change the particulate removal gas cyclone for the purpose of testing different materials of construction. The unit is also installed with a high temperature heat trace and insulation system that is used to maintain the vessel at process operating temperatures. This system has also proven beneficial for preheating the vessel above the syngas moisture dew point prior to placing the unit in service.

\subsection{Char Transfer System 1}

The char transfer system is used to recycle the char collected in both the Gas Filter Char Transfer Drum (D-159) and the Cyclone Char Transfer Drum (D-153) back into the commercial process. The recycle system selected for this slipstream unit has proven to be highly reliable for this process. The Cyclone Char Transfer Drum (D153 ) is an 18-inch diameter by 6-1/2 feet long pressure vessel designed to operate at process conditions. High pressure transport gas is periodically supplied to the drum to recycle the char back to the commercial process. A high temperature heat trace and insulation system is used to maintain the transfer drum at the process operating temperatures. Nuclear level devices are included on the vessel to monitor the level of char accumulation within the drum. The char transfer sequence can be activated either by a previously specified time increment or based upon the level of char accumulation within the drum. 


\subsection{Controls and Data Acquisition ${ }^{1}$}

A Mod5 digital control system, developed by the Dow Chemical Company, provides automated control and operator interface with the slipstream unit. Its primary features include redundant computers and I/O cards to enhance reliability and reduce control system induced interruptions during operation. The program control code for operation of the char cyclone-filtration hybrid unit was developed by ConocoPhillips personnel. The control schemes are readily accessible by the operations staff, which has the capability to modify the code as required. Data acquisition is also accomplished using the Mod5 system. Third party software programs are utilized to graphically display Mod5 data for analysis. 


\subsection{Results}

\subsection{Test Methodology}

\subsubsection{Filter Blinding Life Predictions ${ }^{1}$}

Filter blinding rate is defined as an increase in the resistance to flow through that filter as a function of operating time. Increasing resistance is caused by a number of variables. Small particles can migrate into the filter substrate causing an obstruction in the available flow area. In addition, small particles have an affinity to form bonds (electrostatic, chemical, etc.) with other particles and to the filter media. This bond formation creates a conditioned, or residual, particulate layer that remains on the filter media surface even during a blowback event. Since smaller particles form stronger bonds of attraction, they comprise a significant portion of the residual layer. This reduces surface porosity and further impedes gas flow through the filter. In the E-Gas ${ }^{\mathrm{TM}}$ process, a number of trace elements in the syngas stream contact the candle style filter elements while in a molten and/or vapor form. Many of these trace elements (As, Ge, Sb, etc.) are collected in the non-transient layer and negatively affect the permeability of the filter media. The result is a slow and steady rise in filter media resistance to flow over time. Eventually, the resistance is sufficient to render the blowback system incapable of delivering a reverse flow through the filter media. At that point, the filter media can no longer be regenerated within the system. The blinding limit is well understood for the $\mathrm{E}-\mathrm{Gas}^{\mathrm{TM}}$ process and is used to predict filter life utilizing reliable data depicting resistance as a function of time. 
The residual char layer forms on the outer surface of the filter media during the first 50 to 100 hours of operation for a new set of candle style filter elements. The residual layer remains bonded to the filter media even during the blowback event. This is referred to as the "conditioning period" and is typically characterized by a rapid increase in the filter's resistance to flow, or differential pressure. Once the filter is conditioned, the rise in differential pressure becomes more linear with a noticeable decrease in the rising slope of the data. Therefore, the conditioning period is typically neglected when determining the life of the filter. A linear fit of the data can be used for calculating the blinding life. This method has proven to be highly effective at predicting filter life in both the char filtration slipstream unit and the commercial processes.

\subsubsection{Filter Efficiency ${ }^{1}$}

Filter efficiency is observed at the Wabash plant by a qualitative evaluation. This is done by examining the blinding rate of the backup filter system (V$160 \mathrm{~A} / \mathrm{B})$ in the slipstream process during testing. A rise in differential pressure would typically indicate a gross problem with filter leakage. While this does not provide a quantitative evaluation of the filter efficiencies, for the purposes of these studies, it provides sufficient data to validate acceptable filter efficiencies for the Wabash process. 


\subsubsection{Cyclone and Filter Reliability}

Using the combined cyclone and gas filtration slipstream, both the cyclone internal components and the filter elements were evaluated for reliability in the syngas process. Typical evaluation periods were designed for 250 to 1,000 hours of slipstream operation. Both backup filter (V-160A/B) blinding rates and detailed post-run inspections and analyses were used to evaluate reliability.

\subsubsection{Isokinetic Char Sampling}

The slipstream unit was designed with an isokinetic nozzle to separate the slipstream from the commercial process. This allowed for char samples to be taken from both the cyclone unit as well as the gas filtration unit. Samples were obtained at different times depending on the quantity of char needed for analysis. The sample quantity was used to calculate the percent solids loading of the syngas entering the system as well as determining cyclone efficiency. The particulate size distribution was also useful in specifying the gas filter media.

\subsubsection{Char Recycle Rates}

The char recycle rate of the combined cyclone and gas filtration slipstream was analyzed to provide design specifications for a new E-Gas ${ }^{\mathrm{TM}}$ facility. This rate is defined as the amount of char collected by the hybrid unit in a determinant amount of time. In conjunction with the isokinetic sampling, the char recycle rate could be quantified as the total amount of mass of char per unit of time. 
During operation, both the char recycle rate and cyclone efficiency could be estimated by determining the time required to accumulate a certain level of char within the unit before the next dump cycle. This was feasible as both char transfer drums were constructed to the same specifications and equipped with the same level detection system. However, both char transfer drums would need to be programmed to dump at a previously specified level. This method was susceptible to inaccuracies depending upon the density of the char being accumulated within the drums at the time.

\subsection{Operating Summary}

The Wabash char cyclone-filtration hybrid unit began operation in February of 2006 and had been used in five different test campaigns to date. In total, the system accumulated 1,624 hours of syngas operation with the gasification process operating on petcoke feedstock.

Each test campaign was originally scheduled for at least 250 to 1,000 hours of operation at various filter face velocities to meet the program objections identified in Section 2.3.1, above. Each test campaign is summarized in the following sections below. 


\subsubsection{Cold Flow Testing}

The first campaign carried out for the test program was cold flow testing, or laboratory testing, of the cyclone separator performed by the Original Equipment Manufacturer (OEM) to gain operational insight into the unit before it was installed at the Wabash facility. This was completed in a series of steps. A theoretical computer model of a cyclone separator was generated. From the theoretical model, a pressure drop was calculated across the cyclone separator as a function of flow rate as well as mass separation efficiency. Next, a full scale bench model of the cyclone separator was constructed. Finally, a stream of air infused with test solids offering the same particle size distribution as the char from the Wabash slipstream was injected into the bench scale model and subsequent performance test. The pressure drop as a function of flow rate and mass separation efficiency were measured and compared to the theoretical model as shown in Figure 4.2.1.1. The latter was then used to predict the pressure drop and mass separation efficiency of the cyclone separator based upon the operating conditions of the Wabash facility represented in Figure 4.2.1.2. Results indicated a pressure drop across the cyclone separator of 3.0 psi based upon a flow rate of 2,600 pounds per hour of syngas. The mass separation efficiency was determined to be between $90 \%-95 \%$. This information was subsequently used to develop the operating manuals for the combined cyclone and gas filtration slipstream unit. 
Evaluation of a Combined Cyclone \& Gas Filtration System for Particulate Removal in the Gasification Process Final Report-Results DOE Award No. DE-FC26-02NT41583

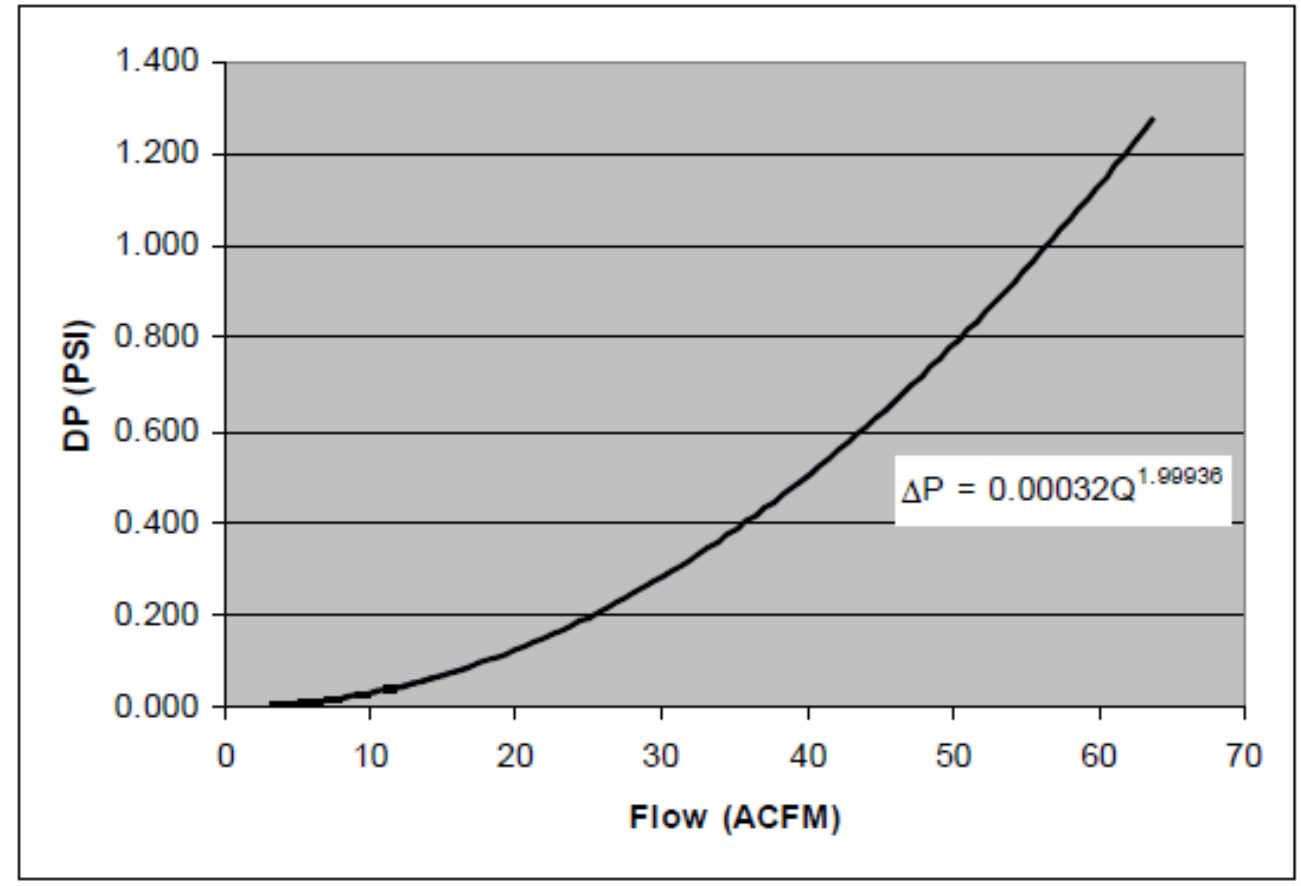

Figure 4.2.1.1 - Differential pressure through the cyclone cold flow test system

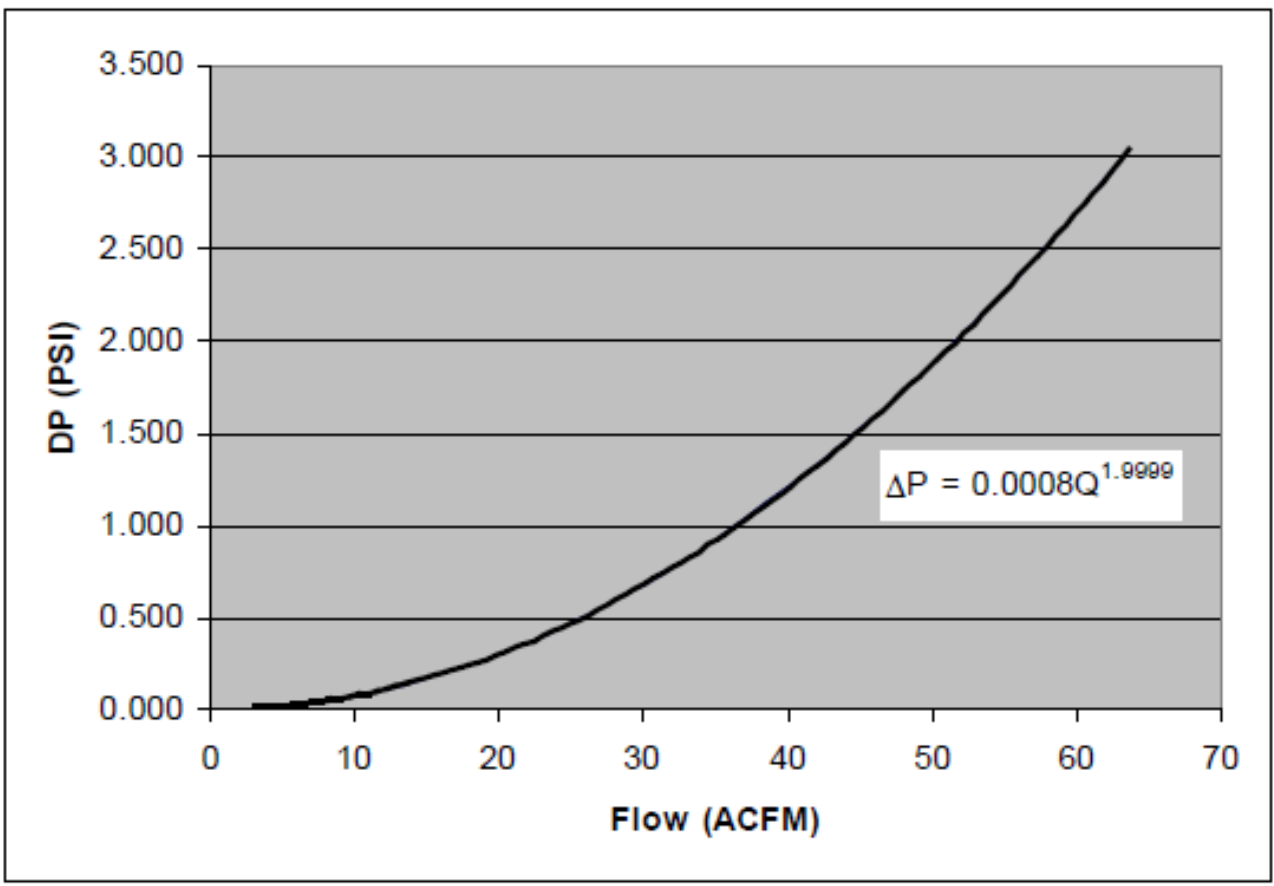

Figure 4.2.1.2 - Projected differential pressure through the hybrid cyclone unit 


\subsubsection{Test Campaign $1(2 / 23 / 2006-3 / 1 / 2006)$}

The initial test of the combined cyclone and gas filtration slipstream unit was conducted with seven (7) 1.5 meter long metal candle filters of the same composition installed in the commercial process in 2006. The test was completed with the cyclone vessel (V-153) bypassed to provide a baseline blinding rate for later data comparison as well as providing conditioned filters for the second test campaign. At the conclusion of this initial test campaign, an isokinetic sample was taken of the char to provide a comparison sample for future campaigns.

Approximately 143 hours were accumulated on the unit during this campaign. The blinding life of the filter elements is depicted in Figure 4.2.2.1. Based upon this data, the estimated blinding life of the filter elements projected to 4,222 hours. At that time, the filter elements would need to be removed from the unit and cleaned. This extrapolated blinding life is less than the blinding life currently achieved within the commercial process. The difference could be attributed to the short amount of operational hours achieved on the subject test filters.

Prior experience would indicate that the filter elements have a conditioning period early on in their blinding life where the differential pressure of the elements climbs rapidly prior to slowing down and reaching a more gradual slope as experienced in the commercial unit. It is opined that during this 
conditioning period, a residual cake layer is formed on the filter element that participates in the filtration process by attracting particulate to it. This particulate on the residual layer of the char will be more easily removed during the blowback process as it is not embedded within the filter media. This allows for a better recovery and slower rise in differential pressure. One of the main objectives of this initial test campaign was to condition the filters prior to running in series with the cyclone separator. Therefore, this campaign test run was ended after a stable rise was seen in the blinding life of the filter elements.

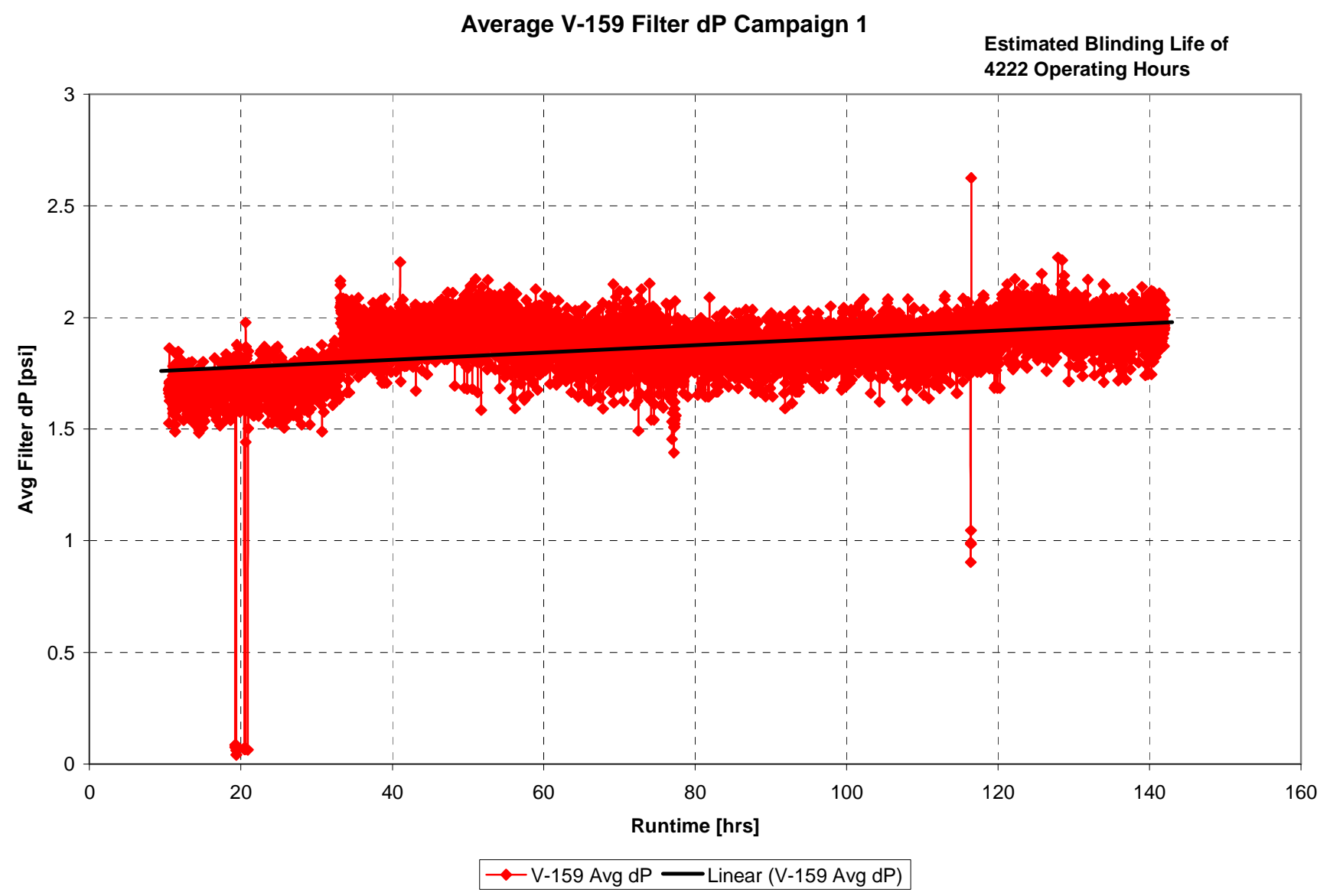

Figure 4.2.2.1-Estimated Blinding Life of Filters from Test Campaign 1 


\subsubsection{Test Campaign 2 (3/7/2006-3/20/2006, 4/7/2006-4/14/2006)}

The second test campaign was the first to utilize the cyclone separation unit, V153. This test employed the same seven (7) 1.5 meter long metal candle filters from the first test campaign that were conditioned for 143 hours with syngas derived from petroleum coke. This campaign was structured to predict blinding life of the filters in the commercial process if combined with a char removal gas cyclone and to determine reliable materials of construction for the cyclone separator unit. The cyclone material used during this time was constructed of a stainless steel alloy. Prior to its installation, thickness checks were performed on the exterior of the cyclone separator to obtain baseline measurements for determining wear rates.

The test accrued 284 hours of run time over the course of two separate runs, but was plagued with several instrumentation errors associated with the level detection equipment and differential pressure transmitter readings. The first run from 3/7/2006 to 3/20/2006 logged 230 hours of run time with gas face velocities beginning at 2.5 feet per minute (fpm) and continually stepped up during the run to $3.5 \mathrm{fpm}$ in $0.5 \mathrm{fpm}$ intervals. The slipstream unit was shut down on several separate occasions during this run to address level detection instrumentation issues. The unit also experienced problems with plugging of the char outlet line from the gas filter vessel (D-159) during the final two days of the run. This required the unit to be shutdown each time to clear the plug. The second run lasted from 4/7/2006 to 4/14/2006, but only accumulated 54 
hours of operation due to a fast actuating blowback valve requiring repair and evidence that the cyclone separator had failed.

The short run times and instrumentation problems with the gas filter vessel limited the data collected to determine the blinding life of the filter elements. The slipstream was able to attain somewhat steady operation while at $3.0 \mathrm{fpm}$ face velocity. From that data, the blinding life for the filter elements was estimated to be 890 hours of operation before the filter elements would need to be removed from the unit and cleaned (See Figure 4.2.3.1). This blinding life is well below the goal of 7,500 hours of continuous operation. However, due to the problems previously stated above, additional testing would need to be conducted to verify the estimated blinding life.

Filter efficiency was also qualitatively examined during this run by measuring the differential pressure trend of the back-up gas filter vessels. The differential pressure remained steady during the entirety of the campaign. While this does not provide quantitative filter efficiency, this is indicative of a minimal amount of char passing through the filter membranes and representing an efficiency that would be suitable in the commercial process.

The average char recycle rates of both the cyclone transfer drum and the gas filter drum were examined during this run by noting char loading times until reaching the set char recycle levels. They were observed to be an average 45- 
50 minutes and 14-18 hours of operating time, respectively. The stark contrast in time shows the efficiency of the cyclone during operation.

The cyclone separator is suspected of failing shortly into the beginning of the second run of this test campaign. This was indicated in the data by a marked increase in the dumping frequency of the gas filter char transfer drum and erratic readings of the cyclone char transfer drum. Post-run inspection of the cyclone showed that the failure of the separator occurred directly in front of the inlet opening where the gas begins to spin and separate into the primary and secondary vortexes as described in section 3.4. Operating time for the cyclone separator is estimated at 248 hours until failure occurred. This amount of time is unacceptable for a commercial unit and different materials of construction will need to be evaluated for the subsequent campaigns. 
Evaluation of a Combined Cyclone \& Gas Filtration System for Particulate Removal in the Gasification Process

Average V-159 Filter dP data Campaign 2

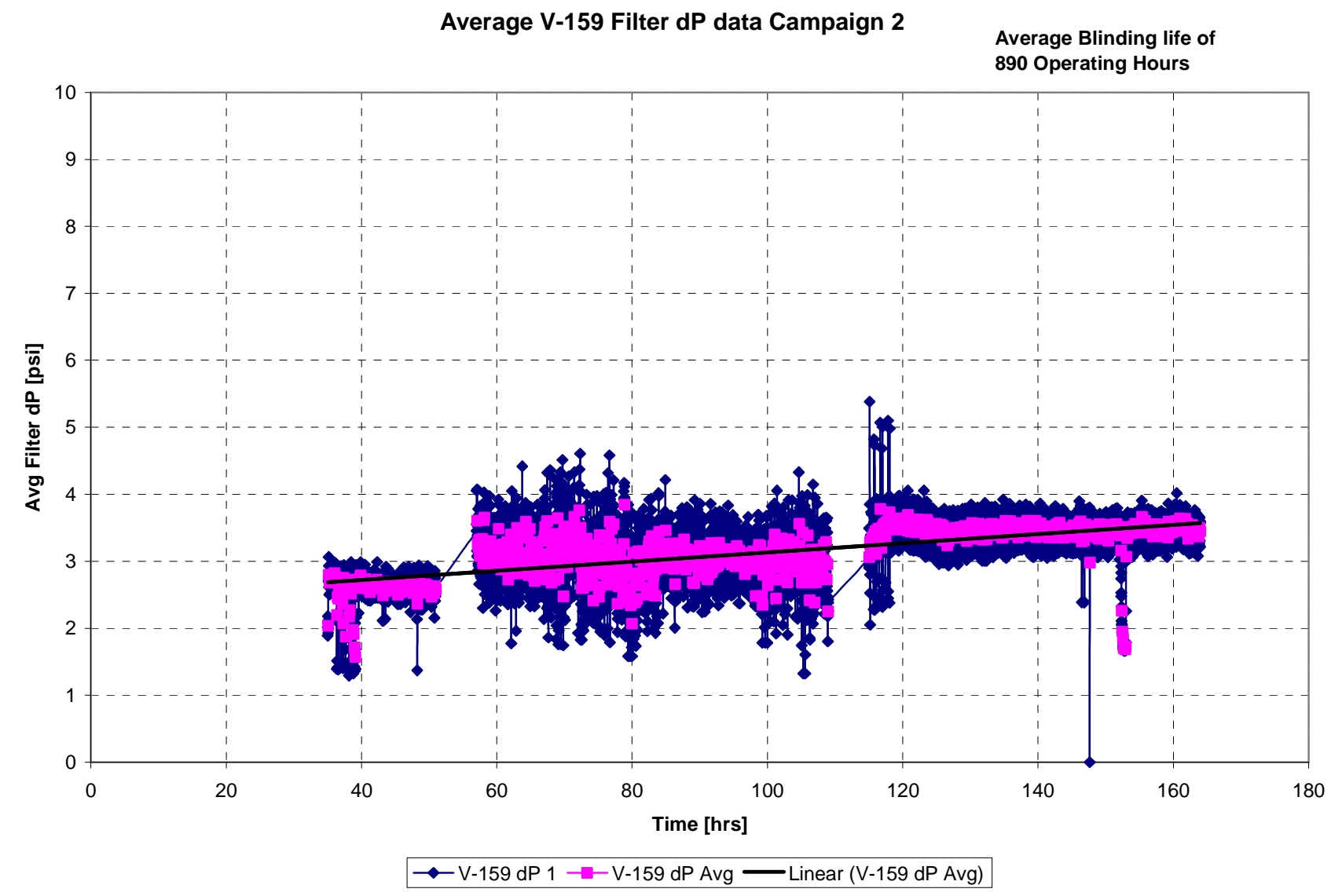

Figure 4.2.3.1 - Estimated Blinding Life of Filters from Test Campaign 2 


\subsubsection{Test Campaign $3(6 / 20 / 2006-6 / 28 / 2006,7 / 25 / 2006-7 / 27 / 2006,8 / 15 / 2006-$}

\section{8/19/2006)}

The third test campaign of the combined cyclone and gas filtration slipstream utilized five (5) 1.5 meter metal candle filters of the same filter media as the commercial vessels but manufactured with a smaller pore size. The theory for the testing was that the smaller pore size would be better suited to capture the finer particulate that the gas filtration vessel would see as a result of the cyclone in operation. The cyclone separator that had failed during the previous test campaign was repaired by replacing the damaged portions of the cyclone separator with a harder, more wear resistant metal alloy. This test was structured to help determine the commercial viability of a new style of metal candle filter with cyclone integration and to test upgraded materials of construction of the cyclone separator unit. Prior to the test campaign beginning the new section of the cyclone separator underwent thickness evaluations in a similar manner as occurred prior to Test Campaign 1 for comparison at a later date

This test campaign accrued approximately 320 operational hours over the course of three runs. The first run occurred from June 20-28, 2006 and amassed 166 hours of runtime. The unit ran at a face velocity of 3.75 feet per minute and was shutdown twice during the run for plugging of the char transfer line from the gas filter vessel (D-159). This run ended due to a commercial plant shutdown on June 28, 2006. The second run occurred from July 25-27, 
2006. The unit accrued 49 hours of runtime at a face velocity of 3.75 feet per minute during this time. The run ended again due to a commercial plant shutdown. The final run of this campaign occurred from August 15-19, 2006. The unit accumulated an additional 105 hours of runtime during this portion of the campaign running at a face velocity of 3.75 feet per minute. The run ended due to a failure of one of the gas filter elements.

Approximately 250 hours of runtime were accumulated on the slipstream unit during this campaign prior to the first noticeable instances of filter failure. An analysis of the data can be seen in Figure 4.2.4.1. From this data, the estimated blinding life of the filters was 1,722 hours of operation. This number is well below the target goal of 7,500 hours of continuous service, but does show an improvement over the projected results from the second campaign. The failed filter was returned to the OEM for analysis. The result of their findings was a split in the metal filter due to the forces of the back pulse cleaning gases. The forces across the filter during the cleaning process were thought to be higher during this campaign than previously experienced due to the smaller pore size of the filter elements creating higher resistance to the back flow.

The efficiency of these filters was also evaluated by notation of the backup filter differential pressure. It can be seen from Figure 4.2.4.2 that the differential pressure increased slightly at the beginning of the campaign during the initial conditioning of the gas filters. After this initial conditioning, there 
was no additional notable increase in the differential pressure prior to the single element failure. Again, this is an indication that the efficiency would be sufficient for the commercial unit.

Data regarding the char recycle rates of both the cyclone transfer drum and the gas filter drum were examined during this run. They were observed to be an average 40-45 minutes and 9-14 hours of operating time respectively. This again showed good efficiency of the cyclone throughout its run. Also as no deviations from these averages was seen during operation, there was no indication of a failure of the cyclone. As a result, the cyclone separator was not examined at the end of this run for erosion resistance. 
Evaluation of a Combined Cyclone \& Gas Filtration System for Particulate Removal in the Gasification Process

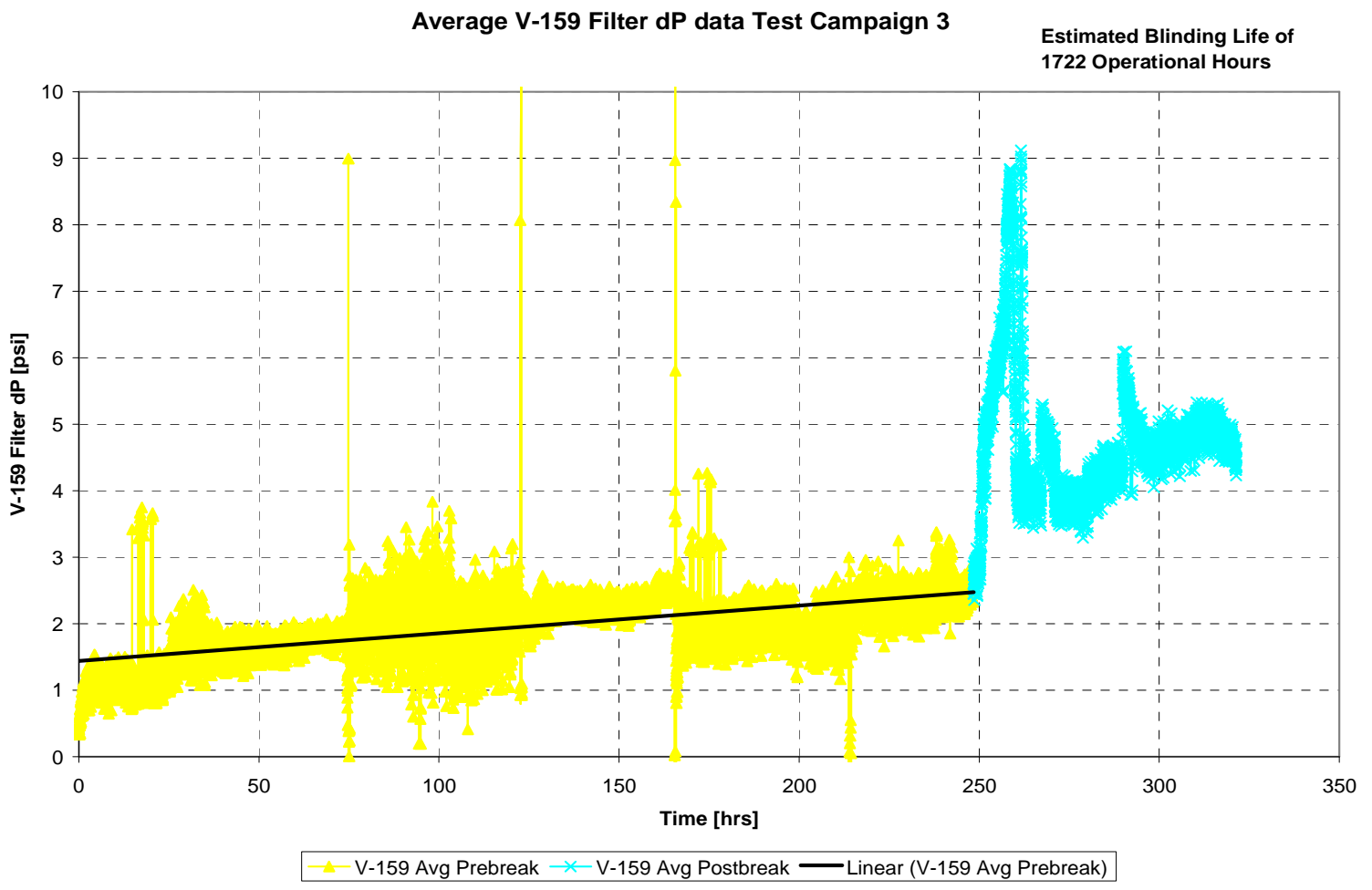

Figure 4.2.4.1 - Estimated Blinding Life of Filters from Campaign 3

V-160 Filter dP data from Test Campaign 3

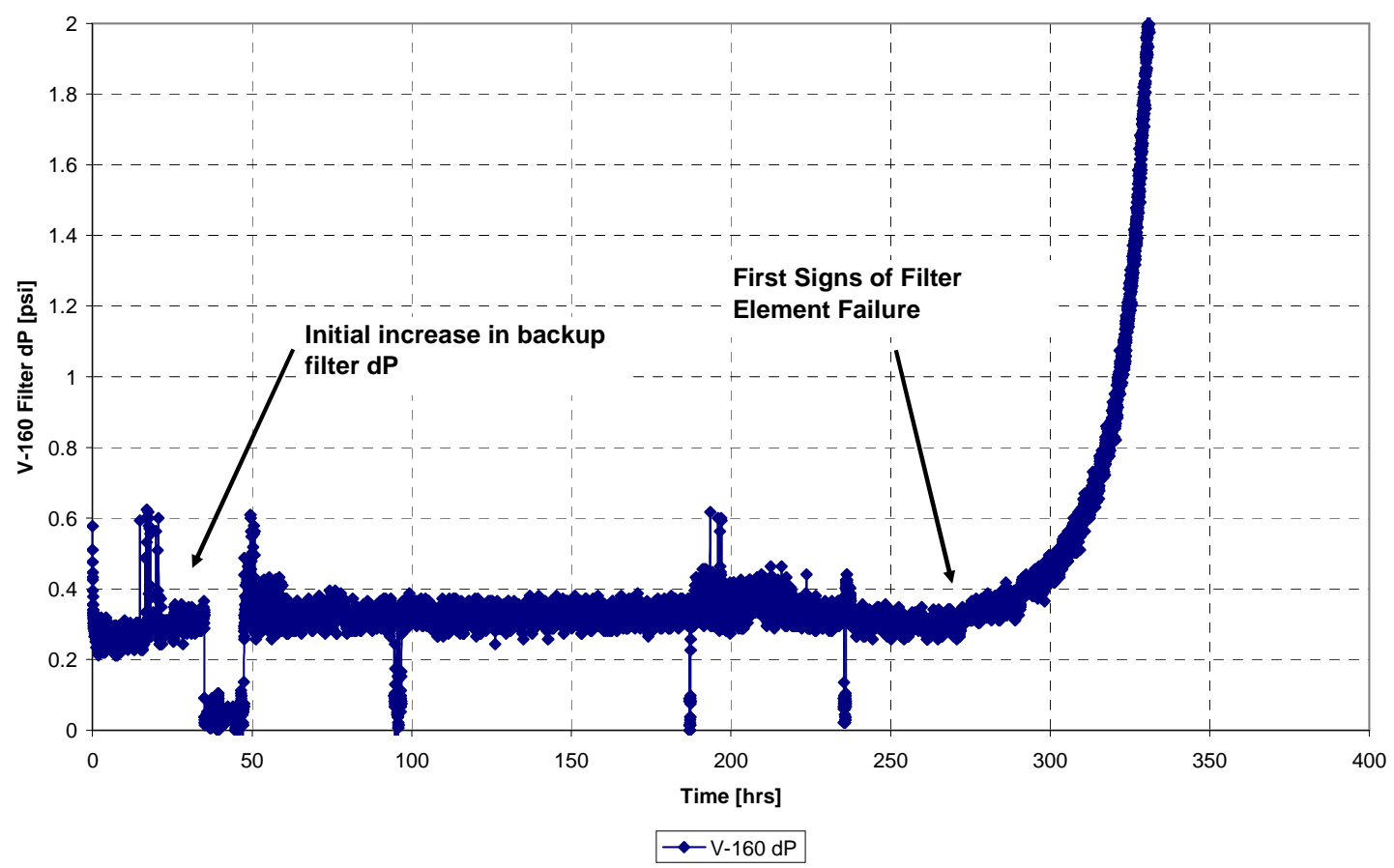

Figure 4.2.4.2 - Backup Filter Differential Pressure from Test Campaign 3 


\subsubsection{Test Campaign $4(9 / 30 / 2006-10 / 10 / 2006,5 / 4 / 2007-5 / 24 / 2007)$}

The fourth test campaign of the combined cyclone and gas filter slipstream unit utilized the same seven (7) 1.5 meter long metal candle filters that had been used in campaigns 1 and 2. The purpose of this test campaign was to further test the viability of conditioned commercially utilized filters with the newly repaired cyclone separator in service.

This campaign attained approximately 500 hours of operating time over two runs. The first run from September 30-October 10, 2006 accumulated 251 operating hours. The unit experienced one shutdown during this operating period due to a plugged char transfer line but was plagued by instrumentation problems throughout the run. The slipstream ran at face velocity of 2.5 feet per minute. This run was ultimately terminated due to a scheduled commercial plant maintenance outage. An isokinetic sample of char was taken from both the D-153 cyclone char transfer drum and the D-159 gas filter char transfer drum prior to the completion of this run and a visual inspection of the cyclone separator was made at this time.

The char sample was sent to an outside company for an analysis of the particle size distribution as well as the cyclone efficiency. The particle size distribution of the char showed positive results with a very small percentage of the larger char particulate flowing into the filter vessel. The majority had been successfully separated and collected by the cyclone. The cyclone efficiency 
was measured in terms of mass of char collected. In the one hour collection time, a total of 266.5 pounds of char were collected in total, 194.75 pounds of the char was collected from the cyclone char transfer drum and 71.75 pounds were collected from the filter char transfer drum. By mass comparison that provides a cyclone efficiency of approximately $73 \%$, lower than the predicted $90 \%-95 \%$. This is believed to be the result of the char transfer drums only being emptied once prior to the sampling. Any char that would not have been evacuated from the drums during this initial dumping step would skew the results of the mass separation efficiency.

The second run of the campaign occurred from May 4-24 of 2007. This run totaled 250 hours of runtime. During this run the slipstream initially ran at a face velocity of 2.5 feet per minute and was increased to 4.0 feet per minute approximately 86 hours into this second run. The unit was shut down once during this run due to plant operations and required shutdowns for plugs in the char transfer line a total of three additional times. The run ultimately ended due to a failure of a gas filter element.

An analysis of the gas filter blinding life is shown in Figure 4.2.5.1. The differential pressure instrumentation was unable to provide reliable data for the first 120 hours of the campaign. From the data available, the blinding life of the filters while experiencing a face velocity of 2.5 feet per minute was estimated to be 3,902 hours. This is again lower than the target of 7,500 
continuous run hours but is similar to the estimated blinding life of 4,211 hours obtained from the conditioning of these filters in Campaign 1. This also gives a comparison for the reduced pore data accumulated in Campaign 3. From these initial tests, it shows that the reduced pore metal candle filters give a lower blinding than the current commercially utilized metal candle filters. Blinding life data for the gas filters running at a face velocity of 4.0 feet per minute could not be obtained due to issues with the instrumentation during this part of the campaign.

As in Campaign 2, no increase was seen in the differential pressure of the back up filter for the slipstream unit during this run. This indicates that these filters provide an acceptable level of filtration efficiency. Issues with the char transfer line plugging as well as instrumentation did not allow for char recycling times to be analyzed during this campaign.

The cyclone separator was visually examined in between the two test runs of this campaign. During the inspection it was noted that the cyclone separator unit began to show some minimal signs of erosion in the inlet section of the separator. Material loss measurements were not conducted at this time. Minimal to no corrosion was seen on the separator as well as its accompanying parts during the inspection. 


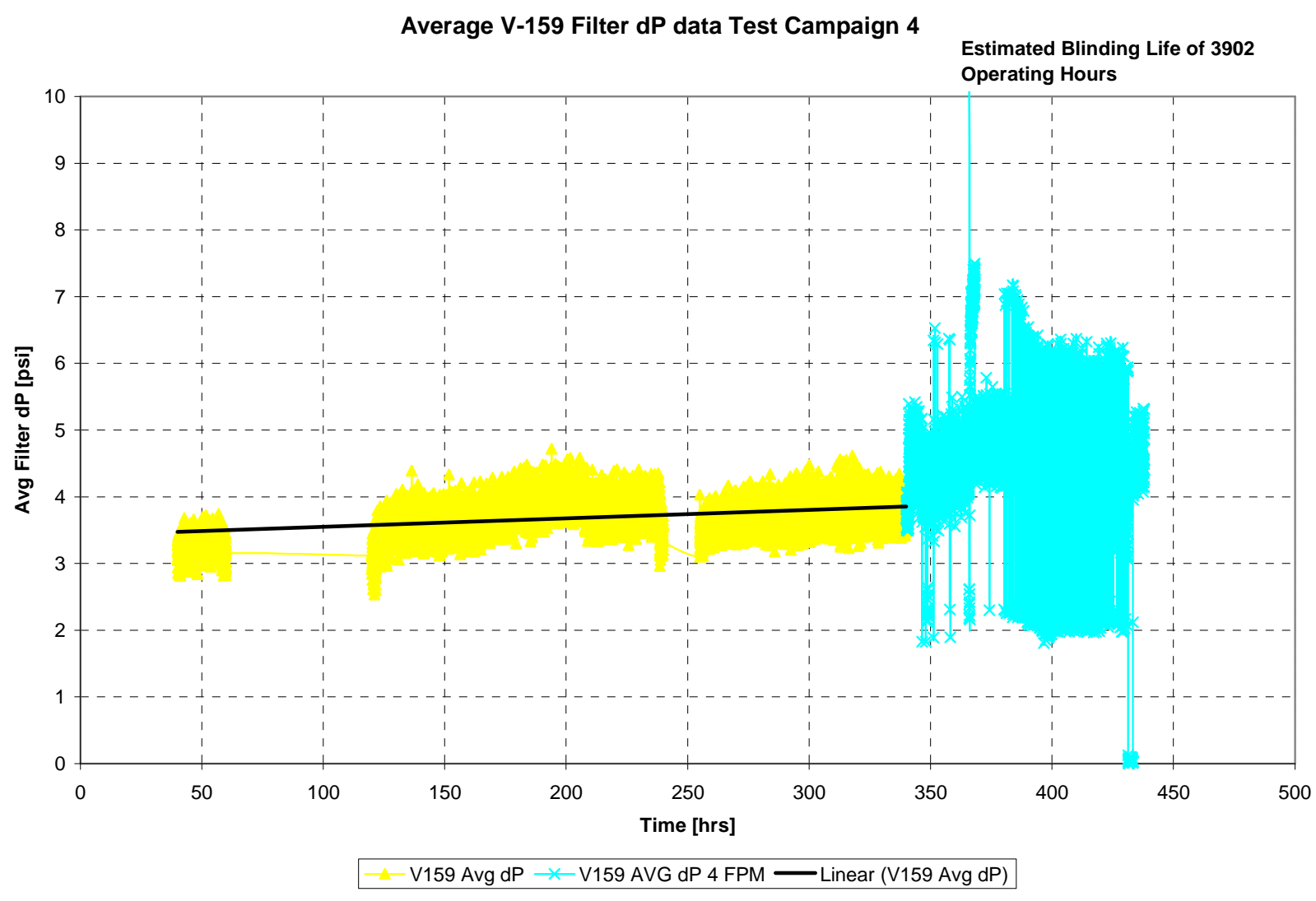

Figure 4.2.5.1 - Estimated Blinding Life of Filters from Campaign 4

\subsubsection{Test Campaign 5 (11/5/2007-11/21/2007, 9/13/2008-9/15/2008)}

Test Campaign 5 utilized seven (7) 1.5 meter long metal candle filters of the same material composition as those used in the commercial process. The main objective of this campaign was to test the blinding life of unconditioned metal candle filters with the use of the cyclone separator.

This test accrued a total of 377 run hours over the two runs. The first run from November 5-11, 2007 accounted for 330 of those run hours. The unit began the run with a face velocity of 2.5 feet per minute and this was raised to 3.3 feet per minute over the course of the first 24 hours of runtime. The face 
velocity remained at this set point over the duration of the run. The unit experienced three shutdowns during the run. Two were caused by plant events outside of cyclone/char hybrid system and the third was caused by a plug in the char outlet line. The run was terminated due to a piping failure upstream of the cyclone vessel. The second run of this campaign accumulated 47 hours of runtime. The test was ended after this short amount of runtime due to high differential pressure experienced on the gas filters and due to a leak that had developed on one of the char transfer valves.

The blinding life of the filters was able to be estimated from the differential pressure data obtained while the filters were experiencing a gas face velocity of 3.3 feet per minute during the first run. The second run did not provide any useable filter blinding data as they experienced high differential pressure shortly after attaining the target face velocity. The curve of this data can be seen in Figure 4.2.6.1. From this graph it can be seen that the blinding life of the filters is estimated to be 1,262 hours of operation. This again is well below of the goal of 7,500 hours of continuous operation. Comparing this figure to the blinding life obtained in Campaign 4 suggests evidence that the blinding life of the filters will be reduced if they do not first go through a conditioning period. The high differential pressure experienced at the end of the second run was a result of filter failure from corrosion attack, attributed to the long idling periods between test runs for this campaign. 
The filter efficiency was examined during this run and no major changes in the backup filter differential pressure were noted. There were slight step changes that occurred when the filter face velocities were increased, but there were not any other noticeable gains during this campaign. From that data, it can be assumed that these metal candle filters with no pre-conditioning run time would produce acceptable levels of filtration efficiency.

Char recycle times were not examined during this campaign as the cyclone and gas filter char transfer drums were programmed to empty at differing predetermined times for this run and not at level set-points.

The cyclone separator was removed from V-153 following this run for a wear analysis. Initial visual inspection of all the components did not show much damage to the cyclone. The repaired section of the cyclone from Campaign 3 appeared to still be intact. There were some slight erosion markings in the interior wall of the separator section of the cyclone, but no apparent uneven wear markings. Also of note were erosion markings on the outer diameters of the vortex finder as well as on the outer diameter of the lower section of the cyclone.

Thickness measurements were in a similar pattern as had been done prior to Campaigns 1 and 3. The areas of the separator that had been repaired prior to Campaign 3 were seen to have the most material loss. The largest material loss 
was noted on the cyclone separator directly across from the inlet piping. This is where the gas flow is forced to turn direction and begins to separate into its primary and secondary vortices. Directly in this flow impingement area there were wall losses ranging from $11 \%-27 \%$. This area had been repaired prior to Test Campaign 3 and replaced with metal that was harder than the stainless steel alloy that had previously been used. Other areas outside of this impingement area saw wall losses ranging from 1\%-6\% of the original thickness.

Based on this data the maximum material loss rate of the repaired sections of the cyclone was seen to be $2.67 \mathrm{E}-5$ inches of material per hour of operation. The maximum material loss rate of the original sections of the cyclone separator and spigot section was seen to be $9.45 \mathrm{E}-6$ inches of material per hour of operation. Given these rates and the original operating thicknesses of the cyclone separator, an estimate of 4,681 and 13,227 operating hours until failure can be made for the upper separator and lower sections of the cyclone respectively. The rates obtained for the upper section are below the target value of 7,500 hours of operation. Additional material testing will be needed to improve this wear rate to meet the target operation of the gas filters. 
Evaluation of a Combined Cyclone \& Gas Filtration System for Particulate Removal in the Gasification Process

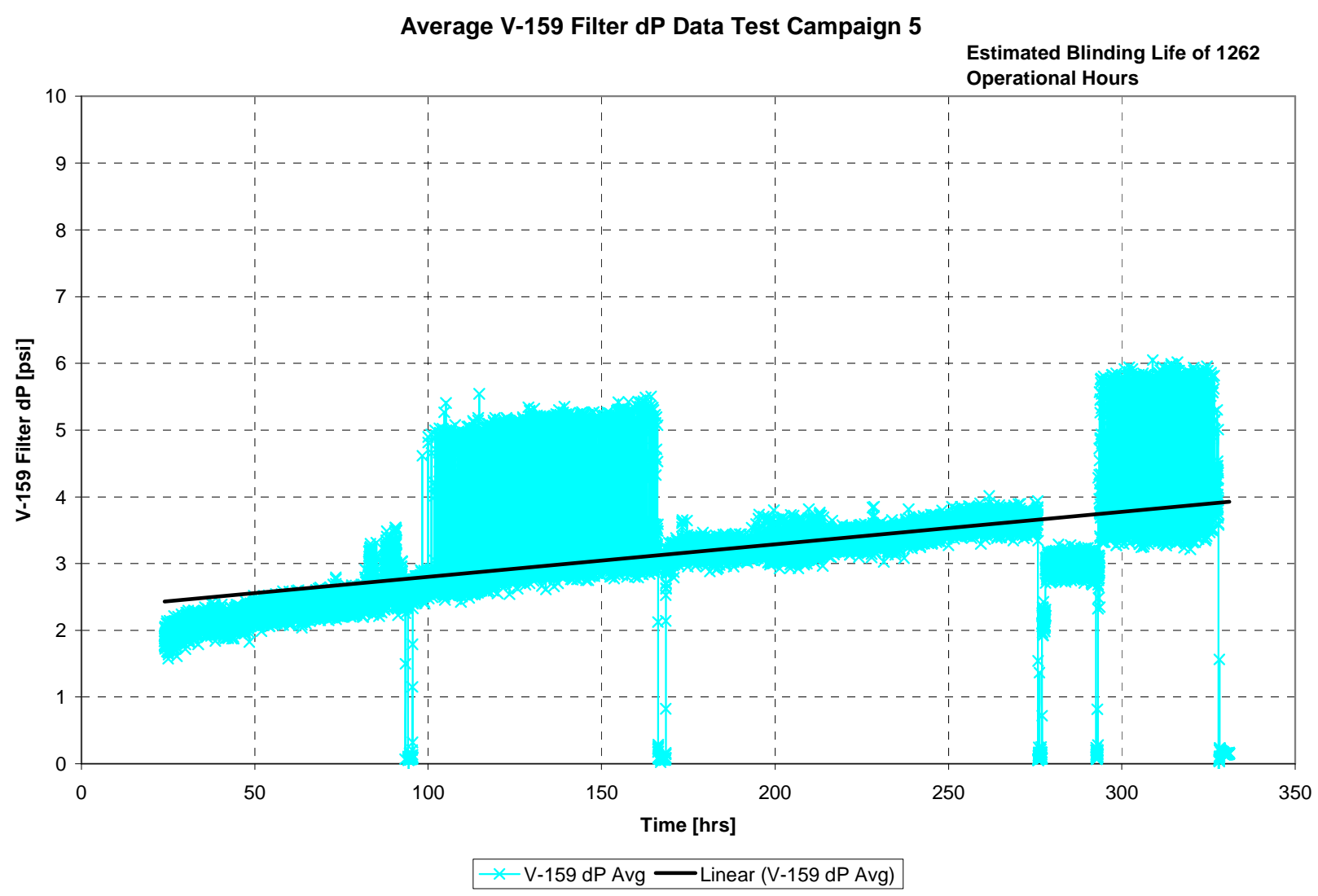

Figure 4.2.6.1 - Estimated Blinding Life of Filters from Campaign 5 


\subsection{Design Guidelines}

\subsubsection{Design of a Commercial Unit}

The design of a commercially sized hybrid cyclone and gas filtration unit would take on many of the characteristics of the hybrid slipstream unit that is installed at the Wabash facility. The design would incorporate a single large cyclone separator vessel to be located just after the high temperature heat recovery unit of the gasification plant. The particulate-laden syngas coming from this unit would enter the cyclone at plant conditions and would undergo a directional flow change in the cyclone causing separation of $90 \%-95 \%$ of the particulate from the syngas. The syngas and remaining 5\%-10\% of the char would exit through the upper portion of the cyclone and enter a single gas filtration vessel for separation. The solids collected in the cyclone vessel would exit the bottom of the vessel and be transported to the facility's char recycling unit for further use in the $\mathrm{E}-\mathrm{Gas}^{\mathrm{TM}}$ process.

The single gas filtration vessel will separate the remaining particulate from the syngas stream through the use of candle filters. A single filter vessel would be needed as opposed to the two filtration vessels currently used at Wabash as they would be able to see a higher filter face velocity as a result of the reduced particle loading from the use of the cyclone separator. The now particulate free syngas would exit the gas filter vessel and continue on to the downstream gas conditioning process. 
The filters will need to be periodically cleaned of the particulate buildup from the syngas cleaning process. The particulate buildup will be removed through the use of recycled syngas blown through the filters in the reverse direction of the dirty syngas flow. The recycled syngas will be stored in an accumulation tank and will be dispersed to the filters through the use of fast acting valves. A process flow diagram of a proposed commercial unit can be seen in Figure 4.3.1.1. 
Evaluation of a Combined Cyclone \& Gas Filtration System for Particulate Removal in the Gasification Process

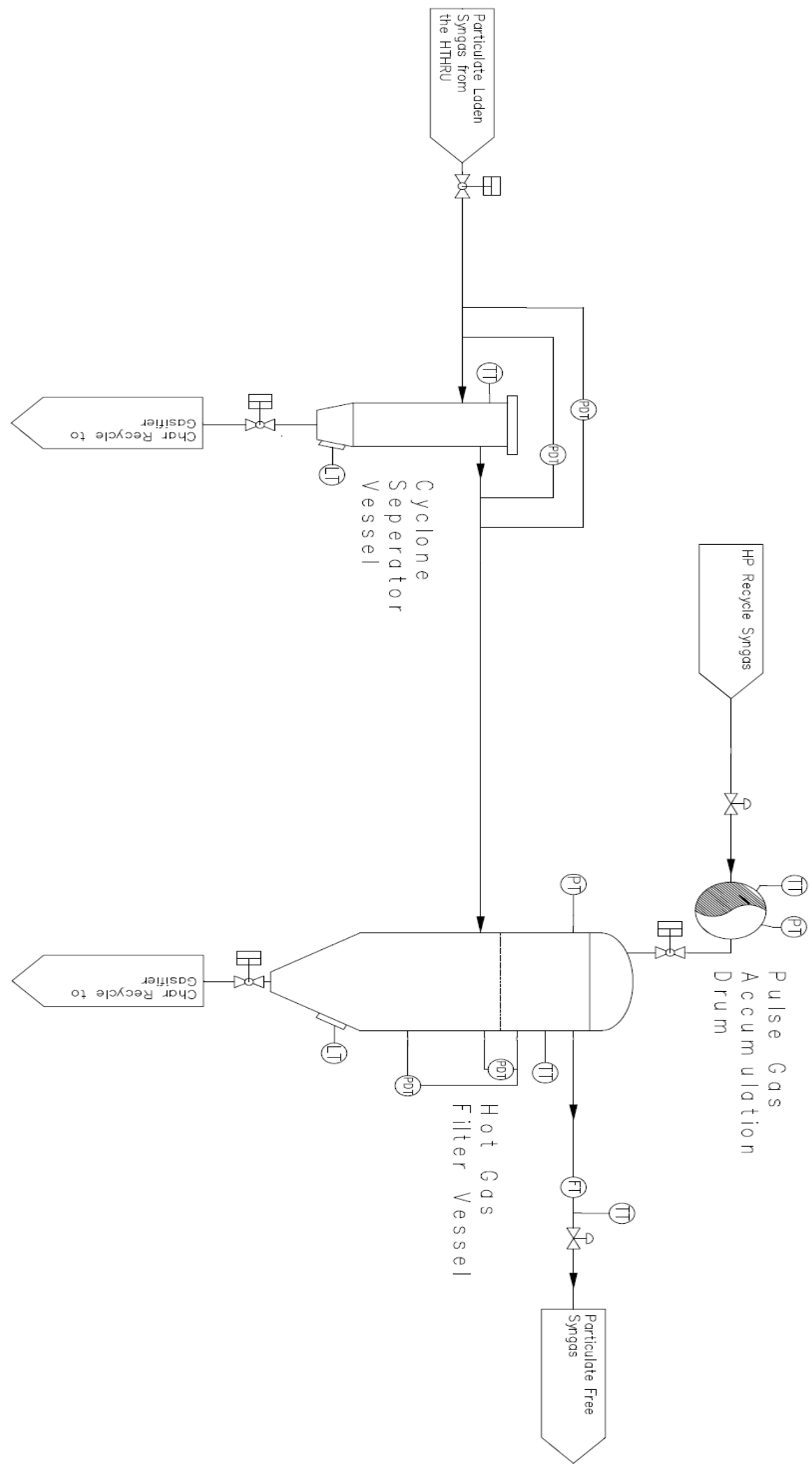

Figure 4.3.1.1 - Proposed Commercial PFD for Combined Cyclone and Gas filtration System 
Evaluation of a Combined Cyclone \& Gas Filtration System for Particulate Removal in the Gasification Process

\subsubsection{Equipment Specifications and Process Parameters}

The equipment described in section 4.3.1 will need to be designed to meet the following specifications and process parameters specified in Tables 4.3.2.1, 4.3.2.2, and 4.3.2.3. These tables were derived from operating conditions at the Wabash facility. 
Table 4.3.2.1 - Equipment Specifications and Process Parameters for Cyclone Vessel

\begin{tabular}{|c|c|c|}
\hline \multicolumn{3}{|c|}{ Equipment Specifications and Process Parameters } \\
\hline Vessel & \multicolumn{2}{|c|}{ Cyclone Separator Vessel } \\
\hline Description & Units & Amount \\
\hline Design Pressure & psi & 500 \\
\hline Design Temperature & $F$ & 800 \\
\hline \multicolumn{3}{|l|}{ Operating Pressure } \\
\hline $\operatorname{Max}$ & psi & 425 \\
\hline \multicolumn{3}{|l|}{ Operating Temperature } \\
\hline $\operatorname{Max}$ & $\bar{F}$ & 750 \\
\hline Syngas Molecular Weight & -- & 21 \\
\hline \multicolumn{3}{|l|}{ Solids Removal Efficiency } \\
\hline Max & $\%$ & 96 \\
\hline Min & $\%$ & 88 \\
\hline Mean Particle Size & $\mu$ & $20-25$ \\
\hline \multicolumn{3}{|l|}{$\begin{array}{l}\text { Particle Size Removed at } \\
\text { Stated Efficiency }\end{array}$} \\
\hline Max & $\mu$ & 10 \\
\hline Min & $\mu$ & 20 \\
\hline Particle Bulk Density & $\mathrm{lb} / \mathrm{ft}^{3}$ & 12.5 \\
\hline \multicolumn{3}{|c|}{\begin{tabular}{|l|l|} 
Typical Syngas Composition & Volume $\%$ \\
\end{tabular}} \\
\hline $\mathrm{H} 2$ & & 25 \\
\hline $\mathrm{CH} 4$ & & 1.2 \\
\hline $\mathrm{CO}$ & & 33.9 \\
\hline $\mathrm{CO} 2$ & & 16.2 \\
\hline $\mathrm{H} 2 \mathrm{O}$ & & 20.1 \\
\hline $\mathrm{N} 2$ & & $\overline{1.3}$ \\
\hline $\mathrm{H} 2 \mathrm{~S}$ & & $\overline{1.3}$ \\
\hline $\mathrm{Ar}$ & & 1 \\
\hline \multicolumn{3}{|c|}{ ppm levels of $\mathrm{NH}_{3}, \mathrm{COS}, \mathrm{HCN}, \mathrm{HCl}$} \\
\hline trace amounts of heav & etals [f & ndent] \\
\hline
\end{tabular}


Table 4.3.2.2 - Equipment Specifications and Process Parameters for Filter Vessel

\begin{tabular}{|c|c|c|}
\hline \multicolumn{3}{|c|}{ Equipment Specifications and Process Parameters } \\
\hline Vessel & \multicolumn{2}{|c|}{ Filter Vessel } \\
\hline Description & Units & Amount \\
\hline Design Pressure & psi & 500 \\
\hline Design Temperature & F & 800 \\
\hline \multicolumn{3}{|l|}{ Operating Pressure } \\
\hline Max & psi & 425 \\
\hline \multicolumn{3}{|l|}{ Operating Temperature } \\
\hline $\operatorname{Max}$ & $\bar{F}$ & 750 \\
\hline Syngas Molecular Weight & -- & 21 \\
\hline Solids Removal Efficiency & $\%$ & $99.95 \%>4$ \\
\hline Particle Size & $\mu$ & $<20$ \\
\hline Particle Bulk Density & $\mathrm{lb} / \mathrm{ft}^{3}$ & 11 \\
\hline Typical Syngas Composition & Volume \% & \\
\hline $\mathrm{H} 2$ & & 25 \\
\hline $\mathrm{CH} 4$ & & 1.2 \\
\hline $\mathrm{CO}$ & & 33.9 \\
\hline $\mathrm{CO} 2$ & & 16.2 \\
\hline $\mathrm{H} 2 \mathrm{O}$ & & 20.1 \\
\hline N2 & & 1.3 \\
\hline $\mathrm{H} 2 \mathrm{~S}$ & & 1.3 \\
\hline $\mathrm{Ar}$ & & 1 \\
\hline \multicolumn{3}{|c|}{ ppm levels of $\mathrm{NH}_{3}, \mathrm{COS}, \mathrm{HCN}, \mathrm{HCl}$} \\
\hline
\end{tabular}


Evaluation of a Combined Cyclone \& Gas Filtration System for Particulate Removal in the Gasification Process Final Report-Results DOE Award No. DE-FC26-02NT41583

Table 4.3.2.3 - Equipment Specifications and Process Parameters for Blowback Gas Accumulator

\begin{tabular}{|c|c|c|}
\hline \multicolumn{3}{|c|}{ Equipment Specifications and Process Parameters } \\
\hline Vessel & \multicolumn{2}{|c|}{ Blowback Accumulator } \\
\hline Description & Units & Amount \\
\hline Design Pressure & psi & 1200 \\
\hline Design Temperature & $\mathrm{F}$ & 400 \\
\hline \multicolumn{3}{|l|}{ Operating Pressure } \\
\hline $\operatorname{Max}$ & psi & 900 \\
\hline \multicolumn{3}{|l|}{ Operating Temperature } \\
\hline $\operatorname{Max}$ & $\bar{F}$ & 300 \\
\hline Syngas Molecular Weight & -- & 21 \\
\hline Typical Syngas Composition & Volume \% & \\
\hline $\mathrm{H} 2$ & & 25 \\
\hline $\mathrm{CH} 4$ & & 1.2 \\
\hline $\mathrm{CO}$ & & 33.9 \\
\hline $\mathrm{CO} 2$ & & $\overline{16.2}$ \\
\hline $\mathrm{H} 2 \mathrm{O}$ & & 20.1 \\
\hline N2 & & 1.3 \\
\hline $\mathrm{H} 2 \mathrm{~S}$ & & $\overline{1.3}$ \\
\hline $\mathrm{Ar}$ & & 1 \\
\hline \multicolumn{3}{|c|}{ ppm levels of $\mathrm{NH}_{3}, \mathrm{COS}, \mathrm{HCN}, \mathrm{HCl}$} \\
\hline trace amounts of heavy $n$ & netals [feed d & ident] \\
\hline
\end{tabular}




\subsection{Equipment Capital Cost Comparison}

For the basis of the capital cost comparison, the costs to purchase and install one cyclone vessel and one gas filtration vessel with a blowback gas accumulator were compared to the costs to install the two gas filtration vessels with blowback gas accumulators at Wabash. Costs for the gas filter vessels and blowback accumulators in each case were based on costs from the Wabash facility in 1995. Costs for the commercial sized cyclone vessel were based on costs estimates completed in 2001 at the beginning of this study. Costs were adjusted for inflation based on the Marshall \& Swift Equipment Cost Index. Cost escalation was estimated to be $132 \%$ increase of the 2001 dollar value to 2010 dollar value, and $141 \%$ increase of the 1995 dollar value to a 2010 dollar value ${ }^{3,4}$. Installation costs were estimated at $2.5 \mathrm{x}$ the equipment costs. A full breakdown of the costs is located in Table 4.4.1 below.

Table 4.4.1 - Capital Cost Comparison of Cyclone Unit versus Current Configuration

\begin{tabular}{|c|c|c|c|c|c|c|c|c|}
\hline \multirow{2}{*}{\multicolumn{3}{|c|}{ Case Description }} & \multicolumn{3}{|c|}{ Wabash } & \multicolumn{3}{|c|}{ Future Plants } \\
\hline & & & \multicolumn{3}{|c|}{2 Hot Gas Filtration Vessels } & \multicolumn{3}{|c|}{$\begin{array}{c}1 \text { Cyclone, } 1 \text { Hot Gas Filtration } \\
\text { Vessel }\end{array}$} \\
\hline Description & Costs [MM\$] & \multirow{2}{*}{\begin{tabular}{|c|}
$\begin{array}{c}\text { Escalation } \\
{[\%]}\end{array}$ \\
$131 \%$
\end{tabular}} & \multirow{2}{*}{$\begin{array}{c}\text { Number of Units } \\
0\end{array}$} & \multicolumn{2}{|c|}{ Total [MM\$] } & \multirow{2}{*}{\begin{tabular}{|c|} 
Number of Units \\
1
\end{tabular}} & \multicolumn{2}{|c|}{ Total [MM\$] } \\
\hline Cyclone Vessel (2001 \$) & 0.43 & & & $\$$ & & & $\$$ & 0.56 \\
\hline Char Filter Vessel (1995 \$) & 2.36 & $141 \%$ & 2 & $\$$ & 7.08 & 1 & $\$$ & 3.32 \\
\hline $\begin{array}{c}\text { Blowback Gas System and } \\
\text { Filter Elements (1995\$) }\end{array}$ & 2.69 & $141 \%$ & 2 & & 8.07 & 1 & $\$$ & 3.78 \\
\hline Subtotal & & & & $\$$ & 15.15 & & $\$$ & 7.66 \\
\hline Installation Costs $(2.5 \mathrm{x})$ & & & & $\$$ & 37.88 & & $\$$ & 19.14 \\
\hline Totals & & & & $\$$ & 53.03 & & $\$$ & 26.79 \\
\hline Potential Savings [MM\$] & & & 26.2 & & & & & \\
\hline Potential Savings [\%] & & & $\overline{49}$ & & & & & \\
\hline
\end{tabular}


As can be seen in Table 4.4.1, the potential capital cost savings for using a cyclone separator vessel in conjunction with a single gas filter vessel at a facility such as Wabash is estimated to be roughly $49 \%$ over the capital costs associated with the current gas filtration system installed at this facility. 


\subsection{Conclusions and Technical Insights}

\subsection{Cyclone Validation}

The slipstream testing of a cyclone separator proved very useful for its validation within the E-Gas ${ }^{\mathrm{TM}}$ process. The use of a cyclone was shown to reduce solids loading on downstream gas filters through the examination of particle size distributions taken from both the slipstream cyclone char transfer drum and gas filter char transfer drum. These distributions showed that the majority of the larger particles of char within the raw syngas were able to be separated by the cyclone.

This reduced solids loading could also be seen through examination of fill times of both the cyclone and gas filter char transfer drums. It was shown during testing that the cyclone had drastically shorter fill times than the gas filter vessel, often averaging 93\%-95\% shorter. These fill times further indicate more solids being separated out of the syngas through use of the cyclone separator and lesser solids loading on the gas filters. These two facts validate the use of a cyclone within the EGas $^{\mathrm{TM}}$ process to reduce solids loading on the downstream gas filters.

\subsection{Cyclone Development}

During the testing, initial operating guidelines for the cyclone and gas filtration process were developed. These guidelines assisted in the creation of the standard operating procedures used during the course of the testing. These procedures will aid in the creation of operating procedures for a future facility. 
The testing also further developed the commercial viability of a cyclone within the E-Gas ${ }^{\mathrm{TM}}$ process by increasing reliability of the cyclone. This was done primarily through the use of erosion evaluations of materials of construction of the cyclone separator. During the study, two different metal alloys were tested as cyclone materials. The first, a stainless steel alloy, was found to not be commercially viable as its erosion rate was much too high and would not produce the continuous runtime that would be required for the commercial process. The second, a more wear resistant metal alloy, was found to show promise during testing with a much lower wear rate. Additional analysis of different materials of construction will need to be completed to ensure the most economically feasible materials of construction can be utilized within a commercial scale cyclone.

\subsection{Filter Development}

The main aspect of filter development was to establish acceptable filter criteria for use downstream of a cyclone separator. These filters would need to be able to accommodate the smaller particulate size and increased face velocities associated with this configuration. During testing, metal candle filters that are currently considered commercially viable were tested as well as the same commercially viable metal candle filters with a reduced pore size. These filters were examined for blinding life during testing, and for their filtering efficiency within the E-Gas ${ }^{\mathrm{TM}}$ process.

By studying the differential pressure of the back up filters installed in the slipstream a general evaluation of filter efficiency could be made to determine whether or not 
the efficiency would be acceptable for use in the commercial process. A true measure of the filtering efficiency would require isokinetic sampling of the clean syngas downstream of the filter elements and could not be accomplished by the current slipstream configuration. By studying the differential pressures of the backup filters in the slipstream, both the standard metal candle filters and the reduced pore metal candle filters were seen to have acceptable rates of filtering efficiency.

The blinding lives of both the standard and reduced pore filters were also examined during this testing. The test filter blinding study results are summarized in Table

\subsection{1 below.}

Table 5.3.1 - Comparison of Filter Blinding Studies

\begin{tabular}{|c|l|l|c|}
\hline Campaign & Filters Used & Filter Testing Purpose & $\begin{array}{l}\text { Estimated } \\
\text { Blinding } \\
\text { Life [hrs] }\end{array}$ \\
\hline 1 & $\begin{array}{l}\text { Standard Commercial } \\
\text { Filters, New Condition }\end{array}$ & $\begin{array}{l}\text { Baseline blinding study, } \\
\text { System shakedown }\end{array}$ & 4222 \\
\hline 2 & $\begin{array}{l}\text { Standard Commercial } \\
\text { Filters, conditioned from } \\
\text { Campaign 1 }\end{array}$ & $\begin{array}{l}\text { Blinding study of } \\
\text { conditioned filters, System } \\
\text { shakedown }\end{array}$ & 890 \\
\hline 3 & $\begin{array}{l}\text { Reduced Pore } \\
\text { Commercial Filters, New } \\
\text { condition }\end{array}$ & $\begin{array}{l}\text { Blinding study of reduced } \\
\text { pore filters }\end{array}$ & 1722 \\
\hline 4 & $\begin{array}{l}\text { Standard Commercial } \\
\text { Filters, conditioned from } \\
\text { Campaigns 1, 2 }\end{array}$ & $\begin{array}{l}\text { Blinding study of } \\
\text { conditioned filters }\end{array}$ & 3902 \\
\hline 5 & $\begin{array}{l}\text { Standard Commercial } \\
\text { Filters, New Condition }\end{array}$ & $\begin{array}{l}\text { Blinding study of new } \\
\text { commercial filters }\end{array}$ & 1262 \\
\hline
\end{tabular}

Some initial comparisons and hypotheses can be made from the data accumulated.

First, the data suggests that use of metal filters that have been through a conditioning period may produce a better blinding life than those that had been introduced to the fine particulate produced by the cyclone without conditioning. This is believed to be 
due to the buildup of the initial residual layer of char on the filter during the conditioning period. As a result of the larger char particles being introduced to the filters residual layer, the smaller particles produced by the cyclone could be more inclined to form bonds with this layer rather than the metal filter media. This residual layer of the char particulate could act as a buffer for the fine cyclone particulate which would make it easier to remove during the blowback process.

The data also suggests that the blinding life of metal filters with a reduced pore size is less than that of the standard pore size metal filters. This is believed to be due to high differential forces the filters had seen during the operating campaign. Although the blowback gas pressure remained constant between Campaign 3 and the remaining campaigns, the local forces exerted on the filters during blowback would have increased as a result of the smaller pore size creating higher blowback gas velocities. These higher velocities could likely have damaged the filters over the course of the campaign which would have resulted in the higher blinding life demonstrated as well as the filter failures that occurred after the short amount of operational hours. Further testing will be needed to establish the optimal filter construction for sustained commercial use as well as to determine the best efficiency with which to run the cyclone. 


\subsection{Recommendations}

The following are recommendations for future testing based on observations from this hybrid cyclone and gas filtration study:

1. The differential pressure measurement instrumentation experienced numerous problems during the course of this study. It is imperative to the filter blinding study to be able to collect this data. As a result, these instruments should be cleared with nitrogen purge at the culmination of every test to ensure they are clear of particulate and capable for more tests. Investigations should also be done to improve the reliability of these instruments.

2. The portions of the cyclone separator that are subject to the highest amounts of potential erosion are located directly across from the inlet of the cyclone where the gas begins rotation and separation into the primary and secondary vortices. Further testing of materials of construction will need to be completed in order to improve the material wear rates of the cyclone separator.

3. Further filter blinding studies will need to be conducted in order to determine the optimal construction characteristics for use in a hybrid cyclone and gas filtration system. These tests should focus on duplicating the results of this study as well as studying blinding life of the filter elements at increased face velocities.

4. Filter blinding studies will need to be conducted on gas filters which have undergone an ex-situ cleaning to extend their useable life. This was not completed during this study but will be important information for cyclone use at future E-Gas ${ }^{\mathrm{TM}}$ facilities. 


\subsection{References}

1 Hickey, Michael J. Slipstream Testing of Particulate Filters at the Wabash River Coal Gasification Project. 2003. Report from the National Energy Testing Laboratory. DOE Award No. DE-FC26-97FT34158.

2 Becthel Corporation et al. Gasification Plant Cost and Performance

Optimization. 2003. Report from the National Energy Testing Laboratory. DOE Award No. DE-AC26-99FT40342

3 Seider, Warren D. et al. Product and Process Design Principles; Synthesis, Analysis, and Evaluation; Second Edition. New York, NY: John Wiley \& Sons, 2004: pp 485.

4 Lozowski, Dorothy. Economic Indicators. Chemical Engineering. August 2010: pp 51-52

5 Bevis, Andy Technical Performance Review. 2007. Internal report from Provair Filtration Group, Hampshire, U.K. 